\title{
Financial Tail Risks in Conventional and Islamic Stock Markets: A Comparative Analysis*
}

\author{
John W. Muteba Mwamba ${ }^{*}$, Shawkat Hammoudeh ${ }^{* *}$ and Rangan Gupta ${ }^{* * *}$
}

\begin{abstract}
Highlights
- BMM and POT used to model financial tail risks

- Conventional and Islamic finance equities considered

- Conventional stock markets fat-left tail and right-tail truncation

- Islamic market has a thin-left tail and right tail without truncation.

-Hence, Islamic markets have large probability of positive returns during crises.
\end{abstract}

\begin{abstract}
This paper makes use of two types of extreme value distributions, namely: the generalised extreme value distribution often referred to as the block of maxima method (BMM), and the peak-over-threshold method (POT) of the extreme value distributions, to model the financial tail risks associated with the empirical daily log-return distributions of the Dow Jones Islamic market (DJIM), the U.S. S\&P 500, the S\&P Europe (SPEU), and the Asian S\&P (SPAS50) indexes during the period between 01/01/1998 and 16/09/2015. Using both the maximum likelihood (ML) method and the bootstrap simulations to estimate the parameters of these extreme value distributions in the left and right tails separately, we find that the empirical distributions of conventional stock markets are characterized by a fat-left tail behaviour, which implies high probability of price drops during a financial crisis, and by a right-tail characterised by a truncation. This finding implies the existence of an upper bound on possible profit during an extreme event. The empirical distribution of the Islamic market is characterised by a thin-left tail behaviour, implying moderately low probability of price drops during a financial crisis, and by a right-tail without truncation implying large probability of positive returns during an extreme event. We divide our sample period into three equal subperiods in order avoid the impact of outliers and structural breaks. The results in each subperiod remain the same and also suggest that for all stock returns the BMM method performs
\end{abstract}

\footnotetext{
* We would like to thank an anonymous referee for many helpful comments. However, any remaining errors are solely ours.

* Department of Economics and Econometrics, University of Johannesburg, Auckland Park, 2006, South Africa. Email: johnmu@uj.ac.za.

** Corresponding author. LeBow College of Business, Drexel University, Philadelphia, PA, USA, and IPAG Business School, Paris, France. Email: hammousm@drexel.edu.

*** Department of Economics, University of Pretoria, Pretoria, 0002, South Africa. Email: rangan.gupta@up.ac.za.
} 
better than the POT method, and that the Islamic stock market is less risky than the conventional stock markets during extreme events.

JEL Classification: G1, G13, G14.

Keywords: tail risk, extreme value distributions, expected shortfall, value at risk.

\section{Introduction}

Extreme episodes, better known as Black Swan events, have the worrying feature that when they occur they have great or extreme effects despite their paucity. These rare events exist in economics, finance, ecology, earth sciences and biometry, among others. However, in economics and finance, these "worst-case" episodes have become more recurrent than before, but they kept their overwhelming consequences. Examples of financial extreme events include the Black Monday of the stock market crash that took place on October 19, 1987, the turmoil in the bond market in February 1994, the 1997 Asian currency crisis, and the 2007/2008 global financial crisis (GFC). Such crises are a major concern for regulators, financial institutions and investors because of their heavy and widespread consequences.

As a consequence, many economists and financial analysts have shown increasing interest in examining the behavior of financial markets, testing financial stress and managing risks during those events. Frank Graham (1930) indicates that drastic events such as the 1920-1923 hyperinflation in Germany offer a much better way to test competing theories than normal events. The current research hopes to do so by taking into account the impact of recent financial crises or extreme events such as the GFC on the risks in different financial markets by applying the extreme value theory.

This paper examines the extraordinary behavior of certain random variables specifically the seemingly different conventional and Islamic stock returns, using the recently developed models known as the extreme value theory methods which quantify risks in left and right tail distributions. During extreme financial crises, these variables are characterized by extreme value changes and have very small probabilities of occurrence. The extreme value theory relies on extreme observations to derive the tail distributions. The risk is measured more efficiently using this model than by modeling the entire distributions of the random variables. Then the link between the extreme value theory and risk management is that the EVT fits extreme quantiles better than the conventional methods for tail-heavy data. In risk 
management, two types of extreme value distributions are frequently used namely the generalized extreme value distribution often referred to as the block of maxima method (BMM), and the Pareto distribution referred to as the peak-over-threshold method (POT).

While these methods have been applied to conventional stock markets to model the tail risks associated with the empirical return distributions, to our knowledge only Frad and Zouari (2014) used the POT method but not the BMM method and applied it to DJIM. Moreover, these authors have not applied this method to compare the left (long position) and right (short position) tail risks in Islamic and regional conventional stock markets which may or may not be ostensibly different markets. Specifically, this study models the tail risks associated with the empirical return distributions of four global financial markets which include the U.S. S\&P 500 index (SP500), the S\&P Europe index (SPEU), the Asian S\&P index (SPAS50) and the Dow Jones Islamic market (DJIM).

Accordingly, our main objective of this study is to use both the BMM and the POT methods in order to model the tail risk behaviour associated with the occurrence of extreme events in the Islamic and conventional stock markets. We also consider the left and the right tails of the empirical return distribution to estimate financial losses as a result of a long or short position on these markets.

The comparison between the Islamic and conventional markets in the tail distributions is relevant and useful because the Islamic stocks are arguably viewed as a viable financial system that can endure financial crises better than the conventional system and can also be used as a diversification vehicle to reduce the risk in conventional portfolios. In essence, Islamic finance may offer products and instruments that are fortified by greater social responsibility, ethical and moral values and sustainable finance.

The Islamic and conventional markets differ in several ways (Dridi and Hassan, 2010; Chapra, 2008). First, Islamic markets prefer growth and small cap stocks, but conventional markets opt for value and mid cap stocks. Second, Islamic finance restricts investments in certain sectors (e.g. alcohol, tobacco, rearms, gambling, nuclear power and military-weapons activities, etc.). Third, unlike the conventional finance, Islamic finance also restricts speculative financial transactions such as financial derivatives like futures and options which have no underlying real transactions, government debt issues with a fixed coupon rate, and hedging by forward sale, and interest-rate swaps, and any other transactions involving items 
not physically in the ownership of the seller (e.g., short sales). Therefore, the research contends that Islamic stock markets have low correlations and limited long-run relationships with the conventional markets, whereby they can provide financial stability and diversification. The more recent literature underlines the superiority of Islamic stock investing in outperforming conventional investments, particularly under the recent global financial crisis (Jawadi et al., 2013).

The novelty of this paper is that it makes use of two extreme value distributions, namely the generalized Pareto distribution and the generalized extreme value distribution, to simultaneously model both the left and right tails of the empirical return distribution in order to understand the effect of each methodology in modelling the tail distribution. The paper uses the maximum likelihood and the bootstrap techniques to estimate the parameters of these two distributions. In addition, unlike previous studies (e.g. Longin, 1996; McNeil and Frey, 2000; Xubiao and Gong, 2009), this paper provides reliable confidence intervals within which the tail risk measures are expected to be found. These confidence intervals are vital in assessing the investor's risk tolerance level. For example, a risk lover investor is likely to have a risk measure that is close to the upper bound of the confidence interval, while a risk averse investor is expected to be near the lower bound of the confidence interval.

The results of this study show that the empirical distributions of conventional stock markets are characterised by a fat-left tail behaviour that implies high probability of price plunge during financial crisis; and by a right-tail characterised by a truncation similar to that of the Fréchet distribution, implying the existence of an upper bound on possible profit during extreme events. However, the empirical distribution of the Islamic market is found to be characterised by a thin-left tail behaviour similar to that of the Gumbel distribution, implying moderately low probability of price drops during financial crises; and by a right-tail without truncation implying large probability of positive returns during financial crises. However, the corresponding tail risk measures are found to be significantly different, depending on the method used. Our results show that for Islamic and conventional stock returns addressed in this study, the BMM method performs better than the POT method by generating positive shape parameters that are consistent with existing literature in $\mathrm{EVT}^{1}$.

\footnotetext{
${ }^{1}$ See for example Bekiros and Georgoutsos (2005); Gilli and Këllezi (2006) or Embrechts, P., Klüppelberg, C. and Mikosch, T. (1997).
} 
To check the robustness of the results, we divide the sample period into three sub-sample periods of equal length and re-estimate the shapes, the scales and the tail risk measures for the left and the right tail of the empirical distributions, using both the POT and the BMM methodologies. Our objective in doing so is to avoid the impacts of outliers and structural breaks and figure out whether we can have the same findings in each sub-period. The results of these sub-sample period are reported in Tables 16 to Table 25. At the one percent significance level, we find similar results in each sub-period and confirm the main findings which attest that Islamic markets are less risky than their conventional counterparts.

Although the POT methodology has become more popular in recent years, our results show that for some stock market returns; it generates negative shape parameters, suggesting that the loss distribution of these stock market returns has an upper bound support in its tails. Practically, this is impossible for stock market returns. Embrechts, Kluppelberg and Mikosch (1997) find similar results for the POT method and argue that this inconsistency might be due to the presence of both autocorrelation and heteroscedasticity in financial time series.

However when the GEV method is used, we find that it generates positive shape parameters for all stock market returns that can capture the negative skewness and excess kurtosis of the distribution of these returns. The presence of such two moments of the return distribution indicates serious deviations from the normal distribution and may suggest that the empirical distribution is asymmetric and exhibit a fat-tailed behaviour. During financial crisis, a positive value of the shape parameter results in a significant excess skewness in the generalized extreme value (GEV) distribution for losses and implies extreme price drops with large probabilities on the right tail ${ }^{2}$ of the GEV distribution. In this case, the GEV distribution nests a special case of the EVT distributions known as the Fréchet distribution characterised by a truncation to its left tail, implying the existence of an upper bound on possible gains for the right tail of the empirical distribution. To date, many EVT models that have intended to deal with both the fat-tail behaviour and the presence of excess skewness and kurtosis in financial asset returns in regional and Islamic markets have failed to highlight the above characteristic features of fat tailed distributions. These features have prevented many of these

\footnotetext{
${ }^{2}$ Since we transform negative returns into positive ones by multiplying them by minus one before fitting them to the GEV distribution, it is worth mentioning that the right tail of the GEV distribution for losses corresponds to the left tail of the empirical distribution that represents losses.
} 
EVT models from being of practical use in risk management during extreme market conditions as they result in unrealistic risk measures.

In addition, the current study attempts to answer the question of whether the Islamic market is different from conventional markets during extreme market conditions. Applying the single analysis of variance (ANOVA) technique to the tail distribution data, we find that the DJIM market is significantly different from the conventional markets, which is likely to be due to its Sharia rules as indicated earlier.

The paper is organized as follows. After this introduction, Section 2 presents a review of the literature on Islamic stock markets and in particular the use of extreme value theory (EVT) distributions in finance. Section 3 discusses the modeling of extreme events using the BMM and the POT methods. Section 4 presents the empirical analysis, while section 5 concludes the paper

\section{Literature review}

Many studies in the general literature have used the EVT to measure the downside risk for conventional markets but to our knowledge this theory has not been applied to a comparison between conventional and Islamic stock markets, although Frad and Zouari, (2014) applied one method of the EVT to the Islamic markets but without comparing them to their conventional counterparts. The EVT has become popular for its ability to focus directly on the tails of the empirical return distribution, and therefore it performs better than other theoretical distributions in predicting extreme events (Dacorogna et al., 1995). To reflect the volatility dynamics in the tail risk estimation, McNeil and Frey (2000) use a GARCH process with EVT and find quite interesting results that favour the extreme value theory. Other studies on EVT-based tail risk estimation include among others Gençay and Selçuk (2004), who investigate the relative performance of market risk models for the daily stock market returns of nine different emerging markets. They use the EVT to generate tail risk estimates. Their results indicate that those tail risk estimates are more accurate at higher quantiles. Using the U.S. stock market data, Longin (2005) shows how EVT can be useful in learning precisely the characteristics of the distributions of asset returns, and finally help to select a better model by focusing on the tails of the distribution. A survey of some major applications of EVT to finance is provided by Rocco (2011). 
The literature on Islamic finance can be divided into four categories. These include the characteristics of Islamic finance, the relative performance of this financial system in comparison to that of other socially responsible and faith-based investments, possible links between Islamic banks and markets and their conventional counterparts, and the potential performance between the two business systems during the recent global financial crisis and the shrinking gap between them. The review in the current study is conducted on the basis of two of the four themes: a general comparison between the performances of the two seemingly different business models, and the relative performance during the recent global financial crises. Studies such as Hammoudeh et al. (2014) and Ajmi et al. (2014) review the other themes.

The more recent strand of the literature compares Islamic and conventional financial markets in terms of relative returns and relative volatility. The comparison also focuses on the relative performance during the recent global financial crisis and relies on certain characteristics of Islamic markets. The markets are represented by indexes from different regions where some are a subset of the Dow Jones indexes, while others belong to the FTSE indexes, among others (Ashraf, 2014). Dania and Malhotra (2013) find evidence of a positive and significant return spillover from the conventional market indexes in North America, European Union, Far East, and Pacific markets to their corresponding Islamic index returns. Sukmana and Kholid (2012) examine the risk performance of the Jakarta Islamic stock index (JAKISL) and its conventional counterpart Jakarta Composite Index (JCI) in Indonesia using GARCH models. Their result shows that investing in the Islamic stock index is less risky than investing in the conventional counterpart.

Girard and Kabir (2008) compare the differences in return performance between Islamic and non-Islamic indexes. After controlling for the firm, market and global factors, the authors do not find significant differences in terms of performance between these types of investments. Using a four factor EGARCH model, Mohammad and Ashraf (2015) examine the determinants of the performance of Islamic stock index returns and find that stock selection and funds rebalancing according to the Sharia screening standards may result in superior performance for investors. They suggest that Sharia screening helps Islamic stock indices to select securities of firms that are growth-oriented and are not financially distressed. 
Balcilar et al. (2015) assess the risk exposures of major Islamic sector indexes with respect to shocks in global conventional markets and find positive risk exposures of Islamic equity sectors with respect to developed market shocks.

Dewandaru et al. (2015) investigate the co-movements between Islamic stock indexes and the major stock indexes across different regions during the major global financial crises. Using the wavelet methods, the authors expose the multi-horizon nature of the co-movements and show that shocks are transmitted via excessive linkages during the recent GFC. However, it is found that the Islamic stock markets exhibit lower exposure to the recent crises. Also using the wavelet decomposition, Rizvi et al. (2015) compare the co-movements for Islamic and mainstream equity markets across the United States and Asia Pacific, with a focus on the behavior of contagion across multiple crises in the last decade and a half. They find that the majority of the global shocks since 1996 have been transmitted from the United States to Asia Pacific through excessive linkages, while the recent subprime crisis unveils a contagion based on the fundamentals. Their results also provide an empirical ground that the Islamic equities and their composition constitute a buffer to financial crises.

The literature also explores the potential importance of Islamic finance, particularly during the recent global financial crisis. Chapra (2008) indicates that excessive lending, high leverage on the part of the conventional financial system and lack of an adequate market discipline have created the background for the global crisis. This author contends that the Islamic finance principles can help introduce better discipline into the markets and preclude new crises from happening. Dridi and Hassan (2010) compare the performance of Islamic banks and conventional banks during the recent global financial crisis in terms of the crisis impact on their profitability, credit and asset growth and external ratings. Those authors find that the two business models are impacted differently by the crisis. ${ }^{3}$ More recently, Jawadi et al. (2014) measure financial performance for Islamic and conventional stock indexes for three regions (the U.S., Europe and the World) before and after the subprime crisis and point to the attractiveness of performance of Islamic stock returns, particularly after the subprime crisis. Arouri et al. (2011) pursue a different approach. While comparing the impacts of the recent global financial crisis on Islamic and conventional stock markets in the same three global

\footnotetext{
${ }^{3}$ There is also a growing literature on Islamic banks (see for example, Cihak and Hesse, 2010; Abd Rahman, 2010; Hesse et al., 2008). Sole (2007) also presents a "good" review of how Islamic banks have become increasingly more integrated in the conventional banking system.
} 
areas and finding less negative effects on the former than the latter, these authors examine diversified portfolios in which the Islamic stock markets outperform the conventional markets. They demonstrate that diversified portfolios of conventional and Islamic investments lead to less systemic risks.

In an earlier study, Ashraf and Mohammad (2014) test the validity of the claim that equities which comply with the Islamic investment principles, based on the Shariah screening, perform better than conventional equities during the declining phase of capital markets. In this regard, the authors compare the performance of global and regional Islamic equity indices with conventional equity indices during the past decade using a logistic smooth transition autoregressive (LSTAR) model. The LSTAR model helps the authors to compare the performances of the Islamic and conventional equity indices across regimes of up and down markets, with the model allowing for a smooth transition from the 'down market' to the 'up market' rather than an abrupt change as in the Markov-switching models. The empirical results indicate that Islamic equity indices, in general, perform better than conventional indices during the period 2000 to 2012. In addition, this study does not find any abnormal returns associated with Islamic equity indices on a global basis, but evidence of positive abnormal returns is observed for regional indices of Europe and Asia. Overall, Ashraf and Mohammad (2014) provide evidence that Islamic equity indices are comparatively less risky than their conventional counterparts, and thus can act as suitable hedges during the downfall of capital markets.

Ashraf (2014) investigates the performance of 29 Islamic stock indices and compares it with that of conventional indices from four major international index providers, using different Shariah screening criteria. The results suggest that the difference in screening criteria does not significantly affect the performance of the Islamic stock indices. The return deviations, if any, are due to the relative riskiness of the Islamic indexes with respect to the relevant benchmarks.

More recently, Yilmaz et al. (2015) investigate the cross interactions between ten major Islamic sectors of the Dow Jones Islamic Market index, using both the consistent dynamic conditional correlation (cDCC) and the dynamic equicorrelation (DECO) models. The authors find that the Islamic equity sectors are highly integrated. More importantly, this result is emphasized further through financial contagion channels in the recent global 
financial crisis. It indicates however that the Islamic equity indexes are also prone to global shocks hitting the world financial system. Furthermore, the result fails to provide evidence of decoupling of the Islamic equity markets from the conventional financial system.

Hkiri et al. (2015) employ the generalized vector autoregressive framework proposed by Diebold and Yilmaz (2012) to measure both total directional and net volatility spillovers between Islamic stock indexes and their conventional counterparts at the sector level among themselves across nine major regions. The results show significant time-varying patterns in the volatility spillovers for all the Islamic and conventional stock indexes and identify the stress transmitters and receivers. Furthermore, they show that the cross-market volatility is strongly affected by several global financial crises.

Mensi et al. (2015) analyse the dynamic spillovers across ten Dow Jones Islamicconventional sector index pairs. Using various multivariate GARCH models, the results show significant time-varying conditional correlations among all the pairs. Moreover, there is evidence that the conditional correlations among all the sector pairs, except those of the telecommunication and utilities sectors, increase after the onset of the recent global financial crisis, suggesting non-subsiding risks, contagion effects and gradual financial linkages. The conventional sectors' risk exposure can be effectively hedged over time in portfolios containing Islamic sector stocks.

Frad and Zouari (2014) use the EVT-POT method and apply it to DJIM to identify the extreme observations that exceed a given threshold for this index. Our study uses both the BMM and POT methods to examine the tail risk for the Islamic and regional conventional stock markets. As indicated earlier, this is the only article that uses EVT in examining the Islamic stock markets.

\section{Methodology}

The process of fitting log-returns series to the extreme value distributions is described below. We will discuss both the BMM and POT methods despite the fact the former gives more reasonable results than the latter. 


\subsection{The Block of Maxima}

Let $X_{1}, X_{2}, \ldots, X_{n}$ be a sequence of iid random variables representing negative returns for the left tail (or positive returns for the right tail) of the distribution of a portfolio with common density function $F$. In what follows, fluctuations of the sample maxima (minima) are investigated. Let $R_{1}=X_{1}$ be the largest rate of return in the portfolio; and $R_{m}=\max \left(X_{1}, X_{2}, \ldots, X_{n}\right)$ the maximal returns or maxima for the right tail of the same portfolio. Corresponding results for the minima (left tail) can be easily obtained by changing the sign of the maxima into negative:

$\min \left(X_{1}, X_{2}, \ldots, X_{n}\right)=-\max \left(-X_{1},-X_{2}, \ldots,-X_{n}\right)$

Assuming that the maxima (minima) are independent and identically distributed, we obtain the density function as follows:

$\operatorname{Pr} o b\left(R_{m} \leq x\right)=\operatorname{Pr} o b\left(X_{1} \leq x, X_{2} \leq x, \ldots, X_{n} \leq x\right)=F(x) \times F(x) \times \cdots \times F(x)=F^{n}(x) ; \quad \forall x \in R$, $n \in N$

where $\mathrm{F}(\mathrm{x})$ is cumulative distribution function of the random variable $\mathrm{x}$.

Following Embrechts, Kluppelberg, and Mikosch (1997), extreme events happen in the tail of the empirical distribution. Therefore, the asymptotic behaviour of the extreme returns/losses $R_{m}$ must be related to the density function in its right-hand tail for positive returns or in its left-hand tail for maximum/largest losses. If the series of maximum/largest losses of a portfolio during each quarterly or yearly block are centered with a mean $d_{n}$ and standard deviation $c_{n}$, then its density function can be expressed as:

$\operatorname{Prob}\left(\left(\frac{\mathrm{R}_{\mathrm{m}}-\mathrm{d}_{\mathrm{n}}}{\mathrm{c}_{\mathrm{n}}}\right) \leq \mathrm{x}\right)=\operatorname{Prob}\left(\mathrm{R}_{\mathrm{m}} \leq \mathrm{u}_{\mathrm{n}}\right)=\mathrm{F}\left(\mathrm{u}_{\mathrm{n}}\right)$

where $u_{n}=u_{n}(x)=c_{n} x+d_{n}, F\left(u_{n}\right)$ is the limit distribution of $R_{m}$, while $d_{n}$ and $c_{n}$ are the location and scale parameters, respectively. Given some continuous density function $H$ such that $\frac{\mathrm{R}_{\mathrm{m}}-\mathrm{d}_{\mathrm{n}}}{\mathrm{c}_{\mathrm{n}}}$ converges in distribution in $H$, Embrechts et al. (1997) show that $H$ belongs to the type of one of the following three density functions:

Fréchet: $\quad \varphi(x)= \begin{cases}0, \text { for } x \leq 0 & \forall \alpha>0 \\ \exp \left(-x^{-\alpha}\right), \text { for } & x>0\end{cases}$ 
Weibull: $\phi(x)=\left\{\begin{array}{lll}\exp \left(-(-x)^{\alpha}\right), & x \leq 0 \\ 1, & x>0 & \alpha>0\end{array}\right.$

Gumbel:

$$
\psi(x)=\exp \left(-e^{-x}\right), \quad x \in R
$$

The density functions are called standard extreme value distributions.

\subsubsection{Generalized extreme value distribution}

Let $X$ be a vector of extreme returns representing the maximum returns (positive or negative) of each quarterly or yearly block period as depicted in Figure 1 below, and denote by $\mathrm{F}$, the density function of $X$. The limiting distribution of the normalised maximum returns $X$ is known to be the generalized extreme value distribution.

Figure 1 shows the hypothetical returns for a long position on the SP500 index during five consecutive years. The maximum returns of each year block denoted by $X_{2}, X_{5}, X_{7}, X_{11}$ and $X_{13}$ have a limiting distribution known as the generalized extreme value distribution expressed as:

$H_{(\xi, \mu, \sigma)}(x)=\exp \left\{-\left(1+\xi \frac{x-\mu}{\sigma}\right)\right\}^{-1 / \xi}$

$\xi$ represents the shape parameter of the tail distribution, $\mu$ its location, and $\sigma$ its scale parameter. When $\xi=\alpha^{-1}>0$, Equation (7) corresponds to the Fréchet type of distributions which includes some well-known fat-tailed distributions such as the Pareto, Cauchy and Student-t distributions. When $\xi=\alpha^{-1}<0$ Equation (7) corresponds to the Weibull type of distributions which includes among others the Pareto type II distribution. When $\xi=0$ Equation (7) corresponds to the Gumbel type of distributions which include most exponential distributions. The Gumbel type of distributions has zero skewness and displays symmetric behaviour in its right and left tails. Its tail index value is infinite, implying that all moments of the distribution are either finite or zero. Generally when $\xi \neq 0$, Equation (7) imposes a truncation of the probability distribution and a distinct asymmetric behaviour in the right and left tails such that when there is high probability of the realisation of an extreme event at one 
tail, there is also an absolute maxima (or minima) in the other tail beyond which values of $\xi$ have zero probability (Embrechts et. al., 1997).

Following Gilli and Kellezi (2006), we re-parameterise the generalized extreme value distribution above in order to include a tail risk measure which is referred to as the "return level":

$$
H_{\left(\xi, \sigma, R^{K}\right)}(x)= \begin{cases}\exp \left\{-\left[\frac{\xi}{\sigma}\left(x-R^{k}\right)+\left(\log \left(1-\frac{1}{k}\right)\right)\right]^{-\xi}\right\}^{-1 / \xi} & ; \forall \xi \neq 0 \\ \left(1-\frac{1}{k}\right)^{\exp \left(-\frac{x-R^{k}}{\sigma}\right)} ; & \forall \xi=0\end{cases}
$$

where $R_{n}^{k}$ represents the return level that is the maximum loss expected in one out of $k$ periods of length $n$ computed as:

$$
R_{n}^{k}=H_{\xi, \mu, \sigma}^{-1}\left(1-\frac{1}{k}\right)
$$

The ML method is used to estimate the parameters of the re-parameterised generalized extreme value distribution as well as their corresponding confidence intervals by maximising its log-likelihood function:

$L\left(R^{k}\right)=\max L\left(\xi, \sigma, R^{k}\right)$

These confidence intervals satisfy the following condition:

$$
L\left(R^{k}\right)-L\left(\hat{\xi}, \hat{\sigma}, \hat{R}^{k}\right)>-\frac{1}{2} \chi_{1-\alpha}^{2}
$$

where $\chi_{1-\alpha}^{2}$ is the $(1-\alpha)^{\text {th }}$ quantile of the Chi-square distribution with 1 degree of freedom.

\subsection{The peak over the threshold approach}

\subsubsection{Generalized Pareto distribution}

Let $X$ be a vector of extreme returns larger than a specific threshold $u$ as depicted in Figure 2 below, and assume that the density function of $X$ is given by $F$. The limiting 
distribution of the extreme returns above a specific threshold is known as the generalized Pareto distribution. The excess density function of $X$ over the threshold $u$ is defined as;

$$
F_{u}(x)=\operatorname{Pr} o b((X-u) \leq x / X>u)=\frac{\mathrm{F}(\mathrm{x}+\mathrm{u})-F(u)}{1-F(u)} ; \mathrm{x} \geq 0
$$

This function is obtained via the generalized Pareto distribution in what is termed as the "peak-over-threshold" method. Figure 2 illustrates how the generalized Pareto distribution fits the extreme returns above a specific threshold value of $u=3$.

This figure shows a hypothetical extreme return distribution marked as 1, 2, 3, 4, 5, 6, and 7 observed during the first half of January, and the y-axis reports their magnitudes. Assume that the return marked as 3 is our threshold. In this case, the returns marked as 4, 5, 6 and 7 are considered here as extreme returns since they are larger than the threshold $u=3$. The limiting distribution of these extreme returns over the threshold $\mathrm{u}=3$ is known as the generalized Pareto distribution (GPD) and is given by the following expression:

$$
G_{\xi, \beta(u)}(x)=\left\{\begin{array}{l}
1-\left(1+\xi \frac{x}{\beta(u)}\right)^{-\frac{1}{\xi}} ; \xi \neq 0 \\
1-\exp \left(-\frac{\mathrm{x}}{\beta(\mathrm{u})}\right) ; \quad \xi=0
\end{array}\right.
$$

where $\xi$ is the shape, and $u$ is the threshold parameter, respectively. It is assumed that the random variable $\mathrm{x}$ is positive and that $\beta(u)>0 ; x \geq 0$ for $\xi \geq 0$ and $0 \leq \mathrm{x} \leq-\frac{\beta(\mathrm{u})}{\xi}$; for $\xi<0$.

The shape parameter $\xi$ is independent of the threshold $u$. If $\xi>0$ then $\mathrm{G}_{\xi, \beta(\mathrm{u})}$ is a Pareto distribution, while if $\xi=0$ then $\mathrm{G}_{\xi, \beta(\mathrm{u})}$ is an exponential distribution. If $\xi<0$, then $\mathrm{G}_{\xi, \beta(\mathrm{u})}$ is a Pareto type II distribution. These parameters are estimated by making use of the ML method. Firstly, an optimal threshold is chosen using the mean excess function plot method introduced by Davidson and Smith (1990). The mean excess function plots the conditional mean of the extreme returns above different thresholds. The empirical mean excess function is defined as: 
$m e(u)=\frac{\sum_{i=1}^{N_{u}}\left(x_{i}-u\right)}{\sum_{i=1}^{N_{u}} I_{u\left(x_{i}>u\right)}}$

where $I_{u}=1$ if $x_{i}>u$ and 0 , otherwise. $N_{u}$ is the number of extreme returns over the threshold $u$. If the empirical mean excess function has a positive gradient above a certain threshold $u$, it is an indication that the return series follows the GPD with a positive shape parameter $\xi$. In contrast, an exponentially distributed log-return series would show a horizontal mean excess function, while the short tailed log-return series would have a negatively sloped function. The parameters of the generalized Pareto distribution are obtained by maximising the following log-likelihood function:

$\mathrm{L}(\xi, \beta)=-\mathrm{N}_{\mathrm{u}} \log (\beta)-\left(1+\frac{1}{\xi}\right) \sum_{\mathrm{i}=1}^{\mathrm{N}_{\mathrm{u}}} \log \left(1+\frac{\xi \mathrm{x}_{\mathrm{i}}}{\beta}\right)$

Embrechts, Klüppelberg and Mikosch (1997) show that the tail distribution of the generalized Pareto distribution can be expressed as follows:

$\hat{F}(x)=1-\frac{N_{u}}{n}\left(1+\hat{\xi} \frac{(x-u)}{\hat{\beta}}\right)^{-\frac{1}{\xi}}$

\subsection{Computing tail risk measures}

Although widely used to measure market risk, the value at risk (VaR) method is not a coherent measure of risk because it doesn't satisfy the sub-additivity condition. Assume that we have a long position in two financial assets $z_{1}$ and $z_{2}$, then sub-additivity means the total risk of a portfolio of these two assets must be less than the sum of the individual asset risks. Consequently, VaR doesn't satisfy the diversification principle. A more coherent risk measure is the Expected Shortfall (ES). The ES measures the expected loss of a portfolio, given that the $\mathrm{VaR}$ is exceeded. In this paper, we compute the VaR as the alpha quantile of the tail distribution in Equation (16), and obtain the ES by adding to the VaR, the mean excess function over the VaR (see Coles, 2001 for derivation):

$\operatorname{VaR}(p)=u+\frac{\hat{\beta}}{\hat{\xi}}\left(\left(\frac{1-p}{N_{u} / n}\right)^{-\hat{\xi}}-1\right)$ 


$$
\begin{aligned}
& E S(p)=E(Y / Y>\operatorname{VaR}(p))=\operatorname{VaR}(p)+E(Y-\operatorname{VaR}(p) / Y>\operatorname{VaR}(p)) \\
& E S(p)=\frac{\operatorname{VaR}(p)}{1-\hat{\xi}}+\frac{\hat{\beta}-\hat{\xi}_{u}}{1-\hat{\xi}}
\end{aligned}
$$

where $p$ is the significance level at which the $\mathrm{VaR}$ is computed. For example, when $p=0.99$, Equations (17) and (18) produce the tail risk measures at the 99 significance level.

\section{Empirical results}

\subsection{Data description}

We make use of the closing daily stock market indexes for the Sharia-compliant stocks in the Dow Jones stock index (DJIM) universe and for conventional stocks in three main regions: the United States, Europe and Asia in the S\&P universe (see, for example, Hammoudeh et al., 2014a; Hammoudeh et al. in press b). As indicated earlier, the four Islamic and regional conventional market indexes under consideration are the US SP500, the Eurozone SPEU, the Asian SPAS50 and the global Islamic market DJIM. The time series for the four stock market indexes are sourced from Bloomberg. The DJIM index represents the global universe of investable equities that have been screened for Sharia compliance. The companies in this index pass the industry and financial ratio screens. The regional allocation for DJIM is classified as follows: $60.14 \%$ for the United States; $24.33 \%$ for Europe and South Africa; and $15.53 \%$ for Asia. The S\&P Euro (SPEU) is a sub-index of the S\&P Europe 350 and includes all Eurozone-domiciled stocks from the parent index. This index is designed to be reflective of the Eurozone market, yet efficient to replicate. The Asian SPAS50 is an index that represents the most liquid 50 blue chip companies in the four Asian countries: Hong Kong, Korea, Singapore, and Taiwan.

The data span from 01/01/1998 to 16/09/2014, making a total of 4358 observations, which include the recent global financial crisis period. Our aim is to model the tail distribution of these financial markets which follow different business models and compute the corresponding left and right risk measures. The left tail represents the losses for an investor with a long position on the market indexes, whereas the right tail represents the losses for an investor being short on the market indexes. Table 1 exhibits the basic statistics 
of the log-returns. It shows that the Asian market SPAS50 index has on average the highest historical rate of return which is equal to $0.0305 \%$, with a corresponding standard deviation of $1.47 \%$ which is the highest among all the indexes. The Islamic market index (DJIM) has the lowest historical average rate of return, with the corresponding lowest standard deviation of $1.0743 \%$. The mean returns for the SP500 and SPEU are reported to be equal to $0.0167 \%$, and 0.0075 with a standard deviation of 1.2582 and 1.4017 , respectively.

A risk-reward analysis exhibited in Figure 3 shows that the Islamic market represented by the DJIM index has the lowest annualised risk of all the markets, and has an annualized rate of return higher than that of the US and the Euro zone markets which are represented by the SP500 and SPEU, respectively. However, the Asian market provides the highest annualized rate of return with the corresponding relatively highest level of risk. Unlike the Islamic markets, the Asian market is characterised by higher uncertainty and political instability that require higher premium than the Islamic market does.

\subsection{Tail estimation results}

Following MacNeil and Frey (2000); we begin by removing the effect of autocorrelation and heteroscedasticity of order one in the log-returns series by fitting them to an Exponential-GARCH (Nelson, 1991) of order one i.e. EGARCH(1,1) model. Table 13 reports the EGARCH $(1,1)$ estimations and the Ljung-Box test for the first 5 lags. All the coefficients in the mean and variance equations are statistically significant. The leverage effect represented by the coefficient gamma is also statistically significant implying that negative returns have a larger impact on the volatility in these markets than positive returns do. The Ljung-Box test results for the first 5 lags show that there is no remaining autocorrelation effect in the data.

The resulting negative and positive residuals i.e. filtered returns are then used to estimate the left and the right tail risks, repsectively. All positive and negative filtered-returns are collected separately, and then fitted to the generalised extreme value distribution using the BMM method, and to the Pareto distribution using the POT method. 
For the generalized extreme value distribution, we first divide our sample period into quarterly blocks ${ }^{4}$ and collect the maximum positive filtered-returns (for the right tail) and the minimum negative filtered-returns (for the left tail) of each quarterly block. The limiting distribution of these maximums (minimums) is known as the generalized extreme value distribution, whose re-parameterised version that is expressed in Equation (8) is used to estimate the shape and scale parameters using the maximum likelihood $(M L)$ method. Table 2 reports the $M L$ estimates of these parameters as well as their confidence intervals. For the purpose of robustness, we report the best estimate and its corresponding bootstrapped value.

Table 2 reports the shape $(\xi)$ and the scale $(\sigma)$ parameters of the re-parameterised GEV function shown in Equation (8), the point estimates and their corresponding confidence intervals for the Islamic and conventional stock market at the $1 \%$ and $5 \%$ significance levels. The maximum likelihood estimates are referred to as $M L$, whereas the bootstrapped estimates are denoted by $B S$. Moreover, $L T(R T)$ refers to the left tail (right tail) of the empirical return distribution, representing the downside risk and upside risk, respectively. We find that the BMM method generates only positive shape parameters for all of the four market indexes used in our study. Based on the $99 \%$ confidence intervals, our results show that the left and right shape parameters of all stock markets are statistically different from zero, except for the shape parameter of the right tail distribution of the Islamic market. In fact, the shape parameter values of the US, Eurozone, and Asian stock markets are found to be equal to $0.324,0.249$, and 0.244 for the left tail respectively, and $0.36,0.326$, and 0.635 for the right tail, respectively. These results suggest that the empirical distributions of these conventional stock markets exhibit a fat left tail behaviour with large probabilities of extreme price drops during financial crises. The estimated shape parameters for these conventional stock markets also suggest that the GEV distribution nest the Fréchet type of distributions whose truncation to the right tail implies the existence of an upper bound on possible profits that can be made in these regional markets.

In comparison with the Islamic market index, we find that the BMM method generates a left tail shape parameter of 0.29 , and a right tail shape parameter of 0.007 for the

\footnotetext{
${ }^{4}$ One of the criticisms of the BMM method is that there is not a standard way of grouping data in blocks of maxima. Given the length of our daily sample period (i.e., 16 years), we believe that grouping the maximums (minimums) in quarterly blocks would result in enough data points to generate unbiased estimates of the generalized extreme value distribution.
} 
global Islamic market. Based on the $99 \%$ confidence intervals, the left tail shape parameter is statistically different from zero, while the right tail shape parameter is statistically equal to zero. This is an indication that the empirical return distribution exhibits a thin left tail behaviour with an infinite tail index similar to that of the Gumbel distribution, implying moderately low probability of price drops during financial crises. It also exhibits a right tail without truncation and with finite higher moments, implying a high probability of large positive return during financial crises. The quantile-quantile plots shown in Figures 6, 7, 8 and 9 confirm that the generalized extreme value distribution best fits the set of quarterly block maximums (minimums) data.

Given the parameters of the re-parameterized generalized extreme value distribution, we thereafter compute one tail risk measure associated with the generalized extreme value distribution, namely the return level for the four markets (see Gilli and Kellezi, 2006). We denote by $R L$ the return level which represents the maximum loss expected in one out of ten quarters. Table 3 reports the $R L$ for both the left and the right tails of the empirical distribution at the $1 \%$ and $5 \%$ significance levels as per the Basel II accord. ${ }^{5}$ Their confidence intervals are reported in Tables 8 and 9. For the purpose of robustness, we also report the bootstrapped return level after 1000 resamples.

For example, using the US SP500 index, one would say that at the $1 \%$ significance level, the maximum loss observed during a period of one quarter exceeds $4.8 \%$ in one out of ten quarters on average for an investor with a long position on the market index (left tail). Figure 4 below highlights the differences in the return level of each market index at both the $1 \%$ and $5 \%$ significance levels. At these levels, we find that due to its Sharia laws, the Islamic market is less risky than the conventional market markets. Both the left and right $M L$ and bootstrapped maximum losses during one quarter are expected to exceed $3.8 \%$ on average in one out of ten quarters for an investor with long and/or short positions in the Islamic market. In contrast, the Asian market index SPAS50 is more risky than the rest of the market indices in our portfolio. Its maximum loss observed during one quarter exceeds $5.8 \%$ in one out of ten quarters on average for an investor with a long position on the index (left tail) and $6 \%$ for an investor with a short position on the index (right tail).

\footnotetext{
${ }^{5}$ The Basel II accords recommend that the VaR be estimated at higher quantile, i.e., the $1 \%$ significance level for the next 10 trading days.
} 
Based on the specific market regulations, we find that in the US market and the Sharia - compliant market which has $64 \%$ of it constiutents in the US maket, the portfolio risk measure is indepedent of the investment strategy used, i.e., the long or the short position. The maximum expected losses in these markets are almost the same for both the long position (left tail) and short positions (right tail) on the market indices. However, in the Eurozone and Asian markets, we find that the short (selling) position generates higher risk than the long only position. We argue that this has to do with the presence of market speculations and short selling regulations, particualrly during the debt crisis.

The POT method proceeds as follows. Using the filtered-return we firstly determine an optimal threshold ${ }^{6}$ value by using the mean excess function method which is described above. We report in Figures 6, 7, 8, and 9 the plots of the mean excess function, the excess distribution and the quantile-quantile distribution for the left tail of the empirical distribution. A visual analysis suggests that the optimal threshold value for the four market indices vary between $3 \%$ and $5 \%$. These values are located at the beginning of a portion of the sample mean excess plot that is roughly linear. Given the large number of values the thresholds can take in this interval of $3 \%$ to $5 \%$, and the resulting subjectivity about the correct threshold value, in this study we follow Mackay, Challenor, and Bahaj (2010), Damon (2009); and Sigauke, Vester and Chikobvu (2012) who suggest the preferable use of the $90^{\text {th }}$ quantile of the empirical return distribution ${ }^{7}$.

We follow the same procedure described above for the BMM method to separate the filtered-returns for the left and right tails for the four stock markets respectively. Using the ML estimation method, we obtain the shape and scale parameters of the generalized Pareto distribution expressed in Equation (13). We also make use of the Bonferroni confidence interval to correct for the sample bias. Two types of confidence intervals are reported: the ML confidence interval and the Bonferroni confidence interval for the left and the right tail

\footnotetext{
${ }^{6}$ The mean excess analysis may be used to select an optimal threshold. An optimal threshold is crucial for obtaining reliable risk measures. Notice that a lower threshold is likely to reduce the variance of the estimates of the Generalized Pareto Distribution and induce a bias in the data above the threshold. A higher threshold reduces the bias but increases the volatility of the estimate of the GPD distribution. See for example Danielsson and de Vries (1997) and Dupuis (1998) for more discussion on this issue. To avoid these issues, we use the $90^{\text {th }}$ quantile of the empirical log-return distribution as the threshold value.

${ }^{7}$ For more discussion on the choice of the optimal threshold value, we refer the interested readers to the following studies Damen (2009); Mackay et al. (2010); Sigauke at al. (2012).
} 
distributions at the $1 \%$ and $5 \%$ significance levels, respectively. The ML and bootstrapped point estimates are reported in Table 4 in the column labelled "best estimate". For example, using the SP500, we observe that, at the $1 \%$ significance level, the ML and bootstrapped estimates of the left tail shape are $0.397 \%$ and $0.011 \%$, respectively. Their corresponding confidence intervals are $-0.034(-1.028)$, and 1.669 (3.99), respectively. These numbers represent the smallest and the largest values these parameters can take.

Unlike the BMM results which are more reliable, the shape parameters generated with the POT method are mostly negative, except for the left tail of the US SP500 and the right tail of the SPAS50 indices. A negative shape parameter basically implies that the distribution of returns has a bounded support in the tail, i.e. has a finite endpoint. The existence of such a bounded support for stock market returns distribution is unrealistic. Table 4 shows that some of the negative shape parameters are also statistically insignificant, i.e. equal to zero, leading to the conclusion that their tail distributions are symmetric. These results highlight the shortcomings of the POT method, most importantly its inability to consistently produce reliable shape parameter estimates for stock market returns.

Table 5 reports the POT-based tail ${ }^{8}$ risk measures for both the left and right tail distributions. Their confidence intervals are reported in Tables 8, 9, 10, and 11 . We find that these tail risk measures are significantly different from the ones obtained with the BMM method. In fact, the BMM-based tail risk measures are between $4.7 \%$ and $6 \%$ for the convetional markets and around 3.6\% for the Islamic markets. Whereas the POT-based risk measures are between $9 \%$ and $27 \%$ for the convetional markets, and around $9 \%$ for the Islamic markets.

However, both the POT and BMM methods suggest that the Islamic stock market is relatively less risky than the conventional stock market during financial crises. To avoid the impact of outliers and strtuctural breaks on our analysis; we divide the sample period into three sub-sample periods of equal length and re-estimate the GEV and GPD parameters in each sub-sample period. We also re-estimate the tail risk measures for the left and the right tails of the empirical distributions, using both the POT and the BMM methodologies. Table 16 to Table 25 report the re-estimation results at the one percent significance level. We find similar results in each sub-period, according to which the Islamic markets are less risky than

\footnotetext{
${ }^{8}$ The estimated tail risk measures are the VaR and the expected shortfall (ES). Theoretically, the ES is equal to the sum of VaR and the average of all losses exceeding the VaR. Therefore, we expect in all cases the VaR estimates to be of less magnitude than the ES estimates.
} 
conventional markets in the tails. These results are quiet surprising given the high correlation between Islamic and conventional markets in general. Table 13 shows that the correlation between the Islamic and the SP500 indices is close to ninety percent. With such a high correlation, one would expect the two markets to comove together during financial crises. Using the ANOVA technique below, our study can confirm that this difference is statistically significant.

Figures 4 and 5 show graphically that the Islamic stock market remains less risky than the regional convetional stock markets during financial crises. This differnce might be due to the regulations on short selling which is not permitted in the Sharia-compliant markets. To test the existence of such difference between the Islamic stock market and the conventional markets, we apply the ANOVA technique to the tail distribution data, i.e. the quarterly maximum and minimum filtered-returns series.

Our aim in applying the ANOVA technique is to study the variability (dynamics) of each stock market during extreme events. In other words, we attempt to see whether the variability of the Islamic market during extreme market conditions is the same as that of conventional stock markets. We therefore test the null hypothesis of equal variability for the four markets, i.e. $\mathrm{H} 0$ : $\mathrm{V} 1=\mathrm{V} 2=\mathrm{V} 3=\mathrm{V} 4$ against $\mathrm{H} 1$ : at least one stock market is different from the others, where V1 is the variability in the SP500 market, V2 is the variability in the SPEU market, V3 is the variability in the SPAS50 market and V4 is the variability in the Islamic DJIM market.

Two results can possibly be obtained from this test. First, if we fail to reject the null hypothesis $\mathrm{H} 0$, it means that there is no difference between the Islamic and the conventional markets during extreme market events. Second, if we reject the null hypothesis it means that at least one market is different from others. In this case, we need to further test two sets of the null hypotheses:

1. The conventional stock markets are not different (they have equal variability during extreme events) against the alternative that they are different. We refer to these hypotheses as $\mathrm{H} 01$ : $\mathrm{V} 1=\mathrm{V} 2=\mathrm{V} 3$, and $\mathrm{H} 11$ : at least one conventional market is different from the rest. 
2. The Islamic stock market is different from each one of the conventional market. In this case, the following hypotheses are formulated: H02: V4=V1 against H12: $\mathrm{V} 4 \neq \mathrm{V} 1$; and $\mathrm{H} 03$ : $\mathrm{V} 4=\mathrm{V} 2$ against $\mathrm{H} 13$ : $\mathrm{V} 4 \neq \mathrm{V} 2$; and $\mathrm{H} 04: \mathrm{V} 4=\mathrm{V} 3$ against $\mathrm{H} 14$ : $\mathrm{V} 4 \neq \mathrm{V} 3$. V1, V2, V3, and V4 are defined as above.

Tables 6 and 7 report the test statistic corresponding to each hypothesis test as well as its p-values. We reject the null hypothesis (H0) of equal variability in all stock markets, and conclude that at least one stock market is different from the others. To find out which market it is, we first test the null hypothesis $\mathrm{H} 01$ of equal variability for all conventional stock markets. We fail to reject this null hypothesis only at the $10 \%$ significance level and conclude that the variability in convnentional stock markets during extreme events is the same. Lastly, we test the null hypotheses of equal variability between the Islamic market and each one of the conventional stock markets; that is, hypotheses H02, H03, and H04. We do reject the null hypotheses for $\mathrm{H} 03$ and $\mathrm{H} 04$ at the 5\% signifiance level, and for $\mathrm{H} 02$ at the $10 \%$ significance level. We conclude that the Islamic DJIM market is significantly different from the convnentional stock markets.

\section{Conclusion}

This paper makes use of two techniques utilized in the extreme value theory literature, namely the BMM method based on the generalized extreme value dostribution and the POT method based on the generalized Pareto distribution. They are used to model the tails of the empirical distributions of the indices of three conventional stock markets and the global Islamic stock market. These indices are represented by the US SP500, the Eurozone SPEU, the Asian SPAS50 and the Islamic DJIM. The main objective of the study is to compute the financial tail risk measures associated with the distributions of these two groups of markets, which follow different business models. To achieve this purpose, the study begins by filering the log-returns series using $\operatorname{EGARCH}(1,1)$. The resulting filtered-returns are then separated in positive and negative series for the left and the right tail distributions respectively, and fitted to both the BMM and POT methods.

For the BMM method, the paper groups the filtered-return series into 67 independent and non-overlapping quarterly blocks and identifies the minimum (maximum) of each block 
as the adequate inputs to this methodology. However, the inputs for the POT method have been identified as the excesses over the threshold of the $90^{\text {th }}$ quantile of the empirical logreturn distribution.

Using the maximum likelihood method and the 1000 bootstrap simulations, we find that the POT shape parameter estimates are inconsistent with most of the existing literature on EVT since most of these shape parameters are negative except for the right tail of SP500, and left tail of SPEU ${ }^{9}$. These negative shape parameters suggest the existence of a bounded support for the distribution of stock market returns. We argue that such negative shape parameter estimates are unrealistic for stock market returns since we cannot practically have such bounded support during financial crises. As a result of such negative shape parameters, the POT-based tail risk measures are found to be largely and unreasonably higher than those obtained with the BMM method.

We find that the BMM method generates statistically significant positive shape parameter estimates for all four market indexes, except for the shape parameter of the right tail of the empirical distribution of the Islamic market. The comparison of these estimated shape parameters shows that the conventional stock markets are characterised by a fat-left tail distribution which implies high probability of price drops during financial crisis. They are also characterized by a right-tail distribution with a truncation similar to that of the Fréchet distribution, which implies the existence of an upper bound support on possible profit during an extreme event. On the other hand, the Islamic market is characterised by a thin left-tail behaviour similar to that of the Gumbel distribution, implying moderately low probability of price drops during financial crises. This market is also categorized by a right-tail without a truncation, implying large probability of positive returns during an extreme event.

We also find that the tail risk measures are significantly different between the conventional and the Islamic markets. These tail risk measures are lower for the Islamic market and higher for the the conventional stock markets. Similar results are also found in the three sub-sample periods. We argue that the tail risk difference has to do with the Islamic

\footnotetext{
${ }^{9}$ Although most of POT- based shape parameters are negative; we find that the right tail of the SP500 and the left tail of the SPEU are statistically insignificant and exhibit a thin tail behaviour. Thin tail distributions cannot model properly extreme events. Therefore the POT-based results are inconsistent with some of the existing literature on EVT modelling see for example McNeil, Frey and Embrocates (2005).
} 
regulations in regard to industry screening, short selling and other excessive risk-taking behaviours in the Islamic market, which are not allowed in the Sharia-compliant market.

To test the existence of such a difference between the Islamic and conventional stock markets; we apply the ANOVA technique to the tail data. Using different statistical hypothesis tests, we find that the Islamic stock market is indeed significantly different from the conventional stock markets during extreme events..

The results of this current study are significantly important since they show clearly that during major crises (i.e. extreme events) the Islamic stock index is not only less risky but also significantly different from the conventional stock markets. Thus, the results come differently to those of the recent studies which show that the Islamic stock market is no different from its counventional counterparts domocilized in different regions.

\section{References}

Arouri, M.H., Lihiani, A. and Nguyen, D. K. (2011). Return and volatility transmission between world oil prices and stock markets of GCC. Economic Modelling 26, 1815-1825.

Ajmi, A. N., Hammoudeh, S., Nguyen, D. K., and Sarafrazi, S., (2014). How strong are the causal relationships between Islamic and conventional finance systems? Evidence from linear and nonlinear tests. Journal of International Financial Markets, Institutions \& Money 28, 213-227.

Arouri, M. E., Ameur, H. B., Jawadi, N., F. Jawadi and Louhichi, W., (2013). Are Islamic finance innovations enough for investors to escape from a financial downturn? Further evidence from portfolio simulations. Applied Economics 45, 3412-3420.

Ashraf, D. 2014. Does Shari'ah Screening Cause Abnormal Returns? Empirical Evidence from Islamic Equity Indices. Journal of Business Ethics 1-20.

Ashraf, D., Mohammad, N., 2014. Matching perception with the reality-Performance of Islamic equity investments. Pacific-Basin Finance Journal, 28(C), 175-189.

Balcılar, M., Demirer, R. and Hammoudeh, S. 2015. Global risk exposures and industry diversification with Shariah-compliant equity sectors. Pacific-Basin Finance Journal, In Press. 
Bekiros, S. and Georgoutsos, D. (2005). Estimation of Value-at-Risk by extreme value and conventional methods: a comparative evaluation of their predictive performance. Journal of International Financial Markets, Institutions and Money 15 (3), 209 -228.

Cihak, M., and Hesse, H., (2010). Islamic Banks and Financial Stability: An Empirical Analysis, Journal of Financial Services Research. Journal of Financial Services Research, 38(2), 95-113.

Coles, S. (2001). An Introduction to Statistical Modeling of Extreme Values, Springer Series in Statistics. Springer, London.

Dacorogna, M. M., Müller, U. A., Pictet, O. V., and DeVries, C. G., (1995). The Distribution of Extremal Foreign Exchange Rate Returns in Extremely Large Data Sets. Preprint, O\&A Research Group.

Damon, L (2009). Modelling tail behaviour with extreme value theory. Risk management 17, 13- 18.

Dania, A., and Malhotra, D. K., (2013). An Empirical Examination of the Dynamic Linkages of Faith-Based Socially Responsible Investing. The Journal of Wealth Management 16(1), 65-79.

Davison, A. C., and Smith, R. L., (1990). Models for exceedances over high thresholds. Journal of Royal Statistical Society 52(3), 393-442.

Danielsson, J., and DeVries, C. G., (1997). Tail index and quantile estimation with very high frequency data. Journal of Empirical Finance 4, 241 - 257

Dewandaru, G., Rizvi, S. A. R, Masih, R., Masih, M., Alhabashi, S. O., 2015. Stock market co-movements: Islamic versus conventional equity indices with multi-timescales analysis. Economic Systems 38, 553-571.

Diebold, F. X., and Yilmaz, K, (2012). Better to give than to receive: Predictive directional measurement of volatility spillovers. International Journal of Forecasting 28, 5766.

Dridi, J.,and Hassan, M., (2010). The effects of global crisis on Islamic and conventional banks: A comparative study. International Monetary Fund Working Paper No, 10/201.

Dupuis, D.J. (1998). Exceedances over high thresholds: A guide to threshold selection. Extremes 1(3), 251-261.

Embrechts, P., Klüppelberg, C. and Mikosch, T. (1997). Modelling Extremal Events for Insurance and Finance. Springer-Verlag, Berlin.

Frad, H., and Zouari, E. (2014). Estimation of value-at-risk measures in the Islamic stock market: Approach based on Extreme Value Theory (EVT). Journal of World Economic 
Research 2014; 3(2): 15-20. Published online July 10, (2014) (http://www.sciencepublishinggroup.com/j/jwer) doi: 10.11648/j.jwer.20140302.11.

Gençay, R., and Selçuk, F., (2004). Extreme Value Theory and Value-at-Risk: Relative Performance in Emerging Markets. International Journal of Forecasting 20, 287-303.

Gilli, M., and Kellezi, E. (2006). An application of extreme value theory to measuring financial risk. Computational Economics 27, 207 - 228.

Girard, E.C., and Kabir, M., (2008). Is there a cost to faith-based investing: Evidence from FTSE Islamic indices. Journal of Investing 17(4), 112-121.

Graham, F. D. (1930). Exchanges, Prices, and Production in Hyperinflation Countries: Germany, 1920-1923. Princeton University Press, Princeton, NJ.

Hammoudeh, S., Mensi, W., Reboredo, J. C., and Nguyen, D. K. (2014a). Dynamic dependence of Global Islamic stock index with global conventional indexes and risk factors. Pacific Basin Financial Journal, 30, 189-206.

Hammoudeh, S., Kim. W.J. and S. Sarafrazi, S. (in press b). Sources of Fluctuations in Islamic, U.S., EU and Asia Equity Markets: The Roles of Economic Uncertainty, Interest Rates. Emerging Markets Finance and Trade (in press).

Hesse, H., Jobst, A. A., and Sole, J., (2008). Trends and challenges in Islamic finance. World Economics 9(2), 175-193.

Hkiri, B., Hammoudeh, S. and Aloui, C. 2015. Total and directional volatility spillovers between conventional and Islamic indexes. Mimeo, Drexel University, Philadelphia, United States.

Jawadi, F., and Sousa, R. A., (2013). Structural breaks and nonlinearity in U.S. and UK public debts. Applied Economics Letters 20(7), 653-657.

Jawadi, F., Jawadi, N., and Louhichi, W. (2014), Conventional and Islamic Stock Price Performance: An Empirical Investigation. International Economics 137, 73-87.

Longin, F. M. (1996). The asymptotic distribution of extreme stock market returns. Journal of Business 69, 3, 383-408.

Longin, F. (2005). The choice of the distribution of asset returns: How extreme value theory can help? Journal of Banking \& Finance29(4), 1017-1035.

Mackay, E. B. L, Challenor, A. S., and Bahay A. S. (2010). On the use of discrete seasonal and directional models for estimation of extreme wave conditions. Ocean Engineering, 37, 425 - 442 . 
McNeil, A. J., and Frey, R. (2000). Estimation of Tail-related Risk Measures for Heteroskedastic Financial Time Series: An Extreme Value Approach," Journal of Empirical Finance, 7, 271- 300.

McNeil, A., Frey, R. and Embrechts, P. (2005). Quantitative Risk Management: Concepts Techniques and Tools. Princeton University Press, Princeton, NJ.

Mensi, W., Hammoudeh, S., Yoon, S-M. 2015. Dynamic correlations and portfolio diversification between Islamic and conventional sector equity indexes. Mimeo, Drexel University, Philadelphia, United States.

Mohammad, $\mathrm{N}$ and Ashraf, D. 2015. The market timing ability and return performance of Islamic equities: An empirical study. Pacific Basin Financial Journal 34, 169-183

Rizvi, S. A. R., Arshad, S. and Alam N. 2015. Crises and contagion in Asia Pacific Islamic v/s conventional markets. Pacific Basin Financial Journal 34, 315-326.

Rocco, M. (2011). Extreme value theory for finance: a survey. Bank of Canada. https://ideas.repec.org/p/bdi/opques/qef_99_11.html

Sigauke, S. Verster A., and Chikobvu, E. (2012). Tail quantile estimation of the heteroskedastic intraday increases in peak electricity demand. Open Journal of Statistics, 2, $435-442$

Sole, J., (2007). Introducing Islamic banks into conventional banking systems, IMF Working Paper, International Monetary Fund, Washington, D. C.

Sukmana, R., Kolid, M., (forthcoming). Impact of global financial crisis on Islamic and conventional stocks in emerging market: an application of ARCH and GARCH method, Asian Academy of Management Journal of Accounting and Finance.

Xubiao H., Gong, P. (2009). Measuring the Coupled Risks: A Copula-Based CVaR Model. Journal of Computational and Applied Mathematics, 223, 2, 1066-1080. 
Table 1: Summary statistics

\begin{tabular}{llccl}
\hline \hline Index & Mean & Std Dev & Skewness & Kurtosis \\
\hline \hline SP500 & 0.0167 & 1.2582 & -0.2039 & 7.9104 \\
SPEU & 0.0075 & 1.4017 & -0.0994 & 4.4679 \\
SPAS50 & 0.0305 & 1.4689 & 0.03 & 5.5 \\
DJIM & 0.0187 & 1.0743 & -0.322 & 6.5891 \\
\hline
\end{tabular}

Table 2: BMM shape and scale estimates ${ }^{10}$

\begin{tabular}{|c|c|c|c|c|c|c|c|c|}
\hline & & & \multicolumn{3}{|c|}{ Alpha $=1 \%$} & \multicolumn{3}{|c|}{ Alpha $=5 \%$} \\
\hline & & & LOWER & POINT & UPPER & LOWER & POINT & UPPER \\
\hline & & & BOUND & ESTIMATE & BOUND & BOUND & ESTIMATE & BOUND \\
\hline \multirow[t]{8}{*}{ SP500 } & LT & ML $\xi$ & 0.089 & 0.324 & 0.574 & 0.136 & 0.324 & 0.524 \\
\hline & & ML $\sigma$ & 0.007 & 0.008 & 0.011 & 0.0071 & 0.00825 & 0.01 \\
\hline & & $\mathrm{BS} \xi$ & & 0.3239 & & & 0.32 & \\
\hline & & $\mathrm{BS} \sigma$ & & 0.0082 & & & 0.0082 & \\
\hline & RT & ML $\xi$ & 0.092 & 0.36 & 0.635 & 0.145 & 0.36 & 0.581 \\
\hline & & ML $\sigma$ & 0.007 & 0.008 & 0.011 & 0.007 & 0.0082 & 0.01 \\
\hline & & $\mathrm{BS} \xi$ & & 0.3605 & & & 0.3604 & \\
\hline & & $\mathrm{BS} \sigma$ & & 0.0082 & & & 0.0082 & \\
\hline \multirow[t]{4}{*}{ SPEU } & LT & $\mathrm{ML} \xi$ & 0.016 & 0.249 & 0.535 & 0.06 & 0.249 & 0.473 \\
\hline & & MLo & 0.007 & 0.009 & 0.011 & 0.0072 & 0.00851 & 0.1034 \\
\hline & & $\mathrm{BS} \xi$ & & 0.2487 & & & 0.2487 & \\
\hline & & $\mathrm{BS} \sigma$ & & 0.0505 & & & 0.00851 & \\
\hline
\end{tabular}

\footnotetext{
${ }^{10} L T$ denotes left tail, while $R T$ refers to right tail. $M L$ and $B S$ refer to the maximum likelihood and bootstraps estimates for the shape $(\xi)$ and the scale $(\sigma)$ parameters, respectively
}

$M L \xi$ : estimate of the shape parameter using the Maximum likelihood method

$M L \sigma:$ estimate of the scale parameter using the Maximum likelihood method

$B S \xi$ : estimate of the shape parameter using the Bootstrap technique

$B S \sigma$ : estimate of the scale parameter using the Bootstrap technique

$N B$ : each Bootstrap technique involves 1000 simulations in order to obtain unbiased estimates 


\begin{tabular}{|c|c|c|c|c|c|c|c|c|}
\hline & RT & ML $\xi$ & 0.089 & 0.326 & 0.554 & 0.137 & 0.356 & 0.51 \\
\hline & & ML $\sigma$ & 0.008 & 0.009 & 0.012 & 0.0079 & 0.00921 & 0.1113 \\
\hline & & $\mathrm{BS} \xi$ & & 0.0326 & & & 0.326 & \\
\hline & & $\mathrm{BS} \sigma$ & & 0.0092 & & & 0.009205 & \\
\hline \multirow[t]{8}{*}{ SPAS50 } & $\mathrm{LT}$ & ML $\xi$ & -0.014 & 0.244 & 0.604 & 0.032 & 0.244 & 0.526 \\
\hline & & ML $\sigma$ & 0.009 & 0.011 & 0.014 & 0.0091 & 0.01082 & 0.0132 \\
\hline & & $\mathrm{BS} \xi$ & & 0.2443 & & & 0.2443 & \\
\hline & & $\mathrm{BS} \sigma$ & & 0.0108 & & & 0.010816 & \\
\hline & $\mathrm{RT}$ & ML $\xi$ & 0.048 & 0.635 & 0.791 & 0.137 & 0.338 & 0.552 \\
\hline & & ML $\sigma$ & 0.009 & 0.011 & 0.013 & 0.0088 & 0.01038 & 0.0128 \\
\hline & & $\mathrm{BS} \xi$ & & 0.3381 & & & 0.3381 & \\
\hline & & $\mathrm{BS} \sigma$ & & 0.0104 & & & 0.010379 & \\
\hline \multirow[t]{8}{*}{ DJIM } & $\mathrm{LT}$ & ML $\xi$ & 0.06 & 0.29 & 0.556 & 0.105 & 0.29 & 0.5 \\
\hline & & $M L \sigma$ & 0.006 & 0.007 & 0.009 & 0.0058 & 0.00674 & 0.0082 \\
\hline & & $\mathrm{BS} \xi$ & & 0.2902 & & & 0.2902 & \\
\hline & & $\mathrm{BS} \sigma$ & & 0.0067 & & & 0.00674 & \\
\hline & $\mathrm{RT}$ & ML $\xi$ & 0.019 & 0.007 & & 0.057 & 0.23 & 0.435 \\
\hline & & $M L \sigma$ & 0.006 & 0.039 & & 0.0063 & 0.0071 & 0.0086 \\
\hline & & $\mathrm{BS} \xi$ & & 0.0071 & & & 0.02302 & \\
\hline & & $\mathrm{BS} \sigma$ & & 0.0386 & & & 0.007095 & \\
\hline
\end{tabular}

Note. See footnotes 4 for Table 2.

Table 3: BMM return levels

\begin{tabular}{llllll}
\hline \hline & & Alpha=1\% & & Alpha=5\% \\
& & ML & Bootstrap & ML & Bootstrap \\
\hline \hline SP500 & Left.RL & 4.8 & 4.78 & 4.778 & 4.777 \\
& Right.RL & 4.8 & 4.81 & 4.805 & 4.8048 \\
\multirow{2}{*}{ SPEU } & Left.RL & 5.1 & 5.05 & 5.053 & 5.0526 \\
& Right.RL & 5.4 & 5.41 & 5.412 & 5.4121 \\
SPAS & & & & & \\
50 & Left.RL & 5.8 & 5.82 & 5.824 & 5.824 \\
& Right.RL & 6.001 & 6.02 & 6.023 & 6.0227 \\
DJIM & Left.RL & 3.901 & 3.92 & 3.92 & 3.9195 \\
& Right.RL & 3.9021 & 3.86 & 3.862 & 3.8619 \\
\hline
\end{tabular}


Table 4: POT shape and scale estimates

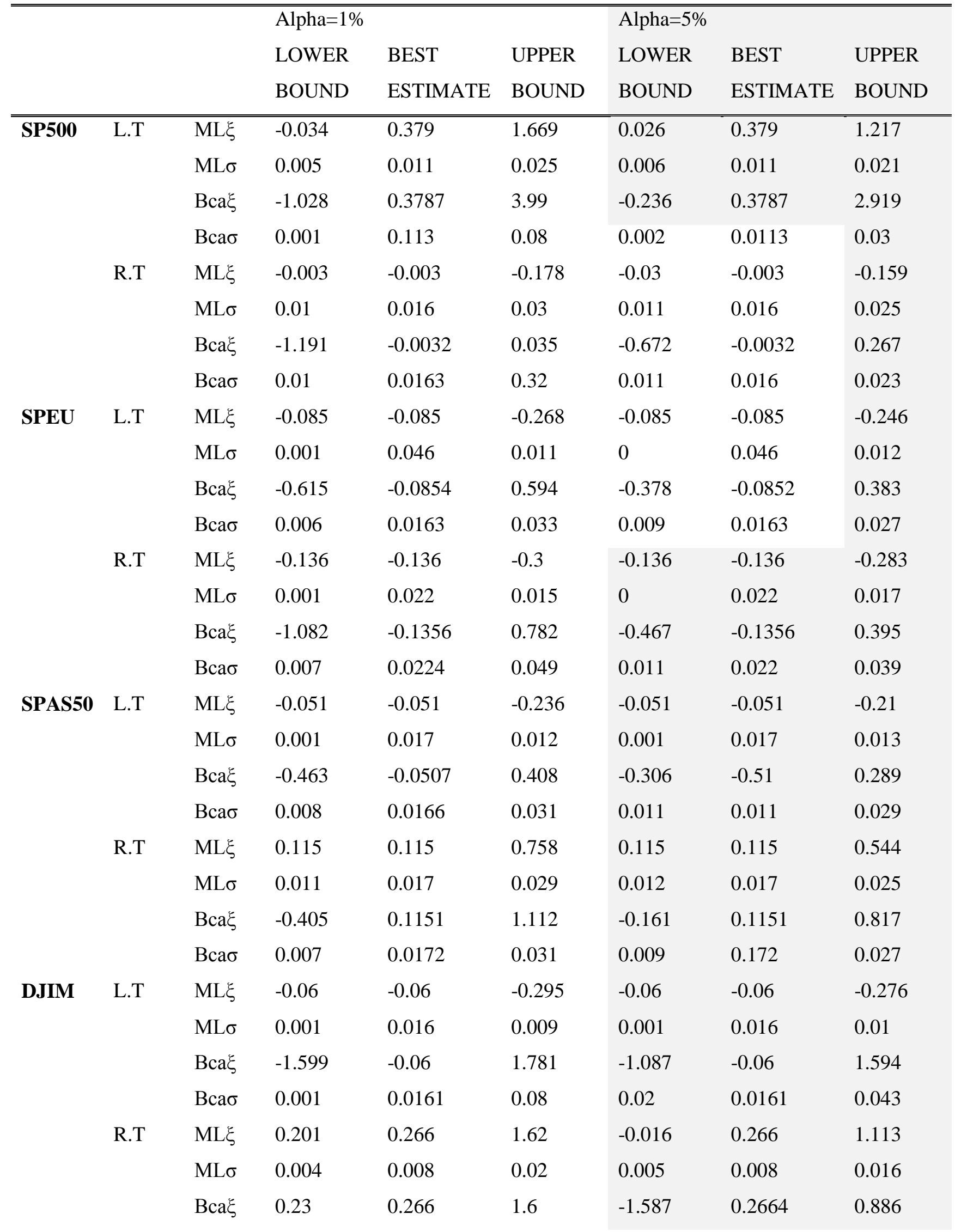


Table 5: POT estimates of VaR and ES

\begin{tabular}{llll}
\hline \hline & & Alpha=1\% & Alpha=5\% \\
\hline \hline SP500 & Left.VaR & 11.06 & 17.15 \\
& Left.ES & 17.79 & 27.15 \\
& Right.VaR & 8.65 & 10.44 \\
& Right.ES & 10.26 & 12.04 \\
SPEU & Left.VaR & 8.22 & 8.22 \\
& Left.ES & 9.31 & 9.31 \\
& Right.VaR & 9.47 & 9.47 \\
& Right.ES & 10.67 & 10.67 \\
SPAS50 & Left.VaR & 9.08 & 9.1 \\
& Left.ES & 10.37 & 10.4 \\
& Right.VaR & 11.53 & 11.53 \\
& Right.ES & 14.58 & 14.58 \\
DJIM & Left.VaR & 7.38 & 7.38 \\
& Left.ES & 8.65 & 8.65 \\
& Right.VaR & 8.024 & 7.02 \\
& Right.ES & 10.18 & 9.61 \\
\hline
\end{tabular}

Table 6: Summary of ANOVA tests for lower tail

\begin{tabular}{lllllll}
\hline \hline & $\begin{array}{l}\text { Sum-of } \\
\text { Squared }\end{array}$ & $\begin{array}{l}\text { Degree } \\
\text { of } \\
\text { Freedom }\end{array}$ & $\begin{array}{l}\text { Mean } \\
\text { Square }\end{array}$ & $\begin{array}{l}\text { F. } \\
\text { Calculated }\end{array}$ & $\begin{array}{l}\text { P } \\
\text { value }\end{array}$ & $\begin{array}{l}\text { F. } \\
\text { Theoretical }\end{array}$ \\
\hline H0:V1=V2=V3=V4 & & & & & & \\
Between Markets & 43.6297 & 3 & 14.54323 & 5.8797 & 0.000672 & 2.6388 \\
$\begin{array}{l}\text { Error } \\
\text { Total }\end{array}$ & 652.9923 & 264 & 2.4725 & & & \\
Decision & 696.622 & 267 & & & Reject Ho & \\
H01: V1=V2=V3 & & & & & & \\
Between Markets & 12.7728 & 2 & 6.4864 & 2.3885 & 0.0944 & 3.0415 \\
Error & 537.7111 & 198 & 2.7157 & & & \\
Total & 550.6839 & 200 & & & Do not Reject & \\
Decision & & & & & Ho @ 10\% &
\end{tabular}


H02: V4=V1

Between Markets

Error

Total

Decision

H03: V4=V2

Between Markets

Error

Total

Decision

H04: V4=V3

Between Markets

Error

Total

Decision
6.9886

308.804

315.7926

21.9468

258.6684

280.6152

38.8648

316.0822

354.947
1

6.9886

2.3394

133

132

21.9468

1.9596

133

33

(3)

RejectOnlyat10\%

0.001066

3.912875

\section{Reject H0}

$\begin{array}{ll}1 & 38.8648 \\ 132 & 2.3946 \\ 133 & \end{array}$

16.2305

0.000094

3.9129
3.912875

Reject HO

Table 7: Summary of NOVA tests for upper tail

\begin{tabular}{|c|c|c|c|c|c|c|}
\hline Source of Variation & $\begin{array}{l}\text { Sum-of } \\
\text { Squared } \\
\end{array}$ & $\begin{array}{l}\begin{array}{l}\text { Degree } \\
\text { of } \\
\text { Freedom }\end{array} \\
\end{array}$ & $\begin{array}{l}\text { Mean } \\
\text { Square } \\
\end{array}$ & $\begin{array}{l}\text { F } \\
\text { Calculated }\end{array}$ & $\begin{array}{l}P \\
\text { value } \\
\end{array}$ & $\begin{array}{l}\text { F } \\
\text { Theoretical }\end{array}$ \\
\hline \multicolumn{7}{|l|}{$\mathrm{H} 0: \mathrm{V} 1=\mathrm{V} 2=\mathrm{V} 3=\mathrm{V} 4$} \\
\hline Between Markets & 54.9709 & 3 & 18.3236 & 6.0139 & 0.00056 & 2.6388 \\
\hline Error & 804.3742 & 264 & 3.0469 & & & \\
\hline Total & 859.3451 & 267 & & & & \\
\hline Decision & & & & & Reject Ho & \\
\hline \multicolumn{7}{|l|}{ H01: V1=V2=V3 } \\
\hline Between Markets & 20.1067 & 2 & 10.0534 & 2.8871 & 0.058087 & 3.041518 \\
\hline Error & 689.4675 & 198 & 3.4822 & & & \\
\hline Total & 709.5742 & 200 & & & & \\
\hline Decision & & & & & $\begin{array}{l}\text { Do not Reject } \\
\text { HO @ } 10 \%\end{array}$ & \\
\hline \multicolumn{7}{|l|}{ H02: V4=V1 } \\
\hline Between Markets & 5.9004 & 1 & 5.9004 & 2.654607 & 0.1056 & 3.912875 \\
\hline Error & 293.3947 & 132 & 2.2227 & & & \\
\hline Total & 299.295 & 133 & & & & \\
\hline Decision & & & & & RejectOnlyat10\% & \\
\hline \multicolumn{7}{|l|}{ H03: V4=V2 } \\
\hline Between Markets & 26.6209 & 1 & 26.6209 & 10.5848 & 0.00148 & 3.91288 \\
\hline Error & 331.9807 & 132 & 2.515 & & & \\
\hline Total & 358.6016 & 133 & & & & \\
\hline Decision & & & & & Reject HO & \\
\hline \multicolumn{7}{|l|}{ H04: V4=V3 } \\
\hline Between Markets & 47.2605 & 1 & 47.2605 & 15.2598 & 0.000149 & 3.912875 \\
\hline
\end{tabular}




\begin{tabular}{llll} 
Error & 408.8121 & 132 & 3.0971 \\
Total & 456.0726 & 133 & \\
Decision & & & \\
\hline
\end{tabular}

Table 8: ML and Bca Estimates of RL when alpha=1\% for BMM method

\begin{tabular}{llllll}
\hline \hline & & LOW & \multicolumn{2}{l}{ POINT } & UPPER \\
& & BOUND & \multicolumn{2}{l}{ ESTIMATE } & BOUND \\
& & ML & ML & Bca & ML \\
\hline \hline SP500 & Left RL & 4.71 & 4.8 & 4.78 & 6.26 \\
& Right & & & & \\
& RL & 4.8 & 4.8 & 4.81 & 6.6 \\
SPEU & Left RL & 5.1 & 5.1 & 5.05 & 6.5 \\
& Right & & & & \\
& RL & 5.4 & 5.4 & 5.41 & 7.2101 \\
SPAS50 & Left RL & 5.8 & 5.8 & 5.82 & 7.9 \\
& Right & & & & \\
& RL & 6.01 & 6.001 & 6.02 & 8.2 \\
DJIM & Left RL & 3.9 & 3.901 & 3.92 & 5.1 \\
& Right & & & & \\
& RL & 3.9 & 3.9021 & 3.86 & 16.4 \\
\hline \hline
\end{tabular}

Table 9: ML and Bca Estimates of VaR when alpha $=5 \%$ for BMM method

\begin{tabular}{llllll}
\hline \hline & & LOW & \multicolumn{2}{l}{ POINT } & UPPER \\
& & BOUND & \multicolumn{2}{l}{ ESTIMATE } & BOUND \\
& & ML & ML & Bca & ML \\
\hline SP500 & Left RL & 3.968 & 4.778 & 4.777 & 6.377 \\
& Right & & & & \\
& RL & 3.931 & 4.805 & 4.8048 & 6.638 \\
SPEU & Left RL & 4.334 & 5.053 & 5.0526 & 6.472 \\
& Right & & & & \\
& RL & 4.503 & 5.412 & 5.4121 & 7.168 \\
SPAS & & & & & \\
50 & Left RL & 4.913 & 5.824 & 5.824 & 7.871 \\
& & & & \multicolumn{2}{c}{34}
\end{tabular}




\begin{tabular}{llllll}
\multicolumn{1}{c}{ Right } & & & & \\
& RL & 4.97 & 6.023 & 6.0227 & 8.17 \\
DJIM & Left RL & 3.301 & 3.92 & 3.9195 & 5.137 \\
& Right & & & & \\
RL & 3.287 & 3.862 & 3.8619 & 4.948 \\
\hline
\end{tabular}

Table 10: ML Estimates of VaR and ES when alpha=1\% for POT method

\begin{tabular}{lllll}
\hline \hline & & LOW BOUND & best ESTIMATE & UPPER BOUND \\
\hline \hline SP500 & Left VaR & -58.94 & 11.06 & 598 \\
& Left ES & 7.12 & 17.79 & 810.37 \\
& Right VaR & -21.35 & 8.65 & 27.75 \\
& Right ES & 7.33 & 10.26 & 120.05 \\
SPEU & Left VaR & -21.79 & 8.22 & 28.81 \\
& Left ES & 7.15 & 9.31 & 142.3 \\
& Right VaR & -20.53 & 9.47 & 35.33 \\
& Right ES & 8.23 & 10.67 & 182.12 \\
SPAS & & & & \\
50 & Left VaR & -20.92 & 9.08 & 27.32 \\
& Left ES & 7.81 & 10.37 & 78.75 \\
& Right VaR & -38.47 & 11.53 & 55.61 \\
& Right ES & 9.32 & 14.58 & 164.5 \\
DJIM & Left VaR & -22.62 & 7.38 & 125.74 \\
& Left ES & 0.01 & 8.65 & 183.39 \\
& Right VaR & 23.01 & 8.024 & 118.027 \\
& Right ES & 0.31 & 10.18 & 162.03 \\
\hline \hline
\end{tabular}


Table 11: ML Estimates of VaR and ES when alpha=5\% for the POT method

\begin{tabular}{|c|c|c|c|c|}
\hline & & LOW & best & UPPER \\
\hline & & BOUND & ESTIMATE & BOUND \\
\hline & Left & & & \\
\hline \multirow[t]{6}{*}{ SP500 } & VaR & -92.85 & 17.15 & 74.254 \\
\hline & Left ES & 0.01 & 27.15 & 248.65 \\
\hline & Right & & & \\
\hline & $\mathrm{VaR}$ & -29.56 & 10.44 & 28.7 \\
\hline & Right ES & 8.75 & 12.04 & 57.61 \\
\hline & Left & & & \\
\hline \multirow[t]{6}{*}{ SPEU } & VaR & -21.78 & 8.22 & 16.47 \\
\hline & Left ES & 7.46 & 9.31 & 32.5 \\
\hline & Right & & & \\
\hline & VaR & -20.53 & 9.47 & 19.48 \\
\hline & Right ES & 8.6 & 10.67 & 38.03 \\
\hline & Left & & & \\
\hline \multirow[t]{6}{*}{ SPAS50 } & VaR & -20.9 & 9.1 & 17.4 \\
\hline & Left ES & 8.1 & 10.4 & 30.9 \\
\hline & Right & & & \\
\hline & $\mathrm{VaR}$ & -38.47 & 11.53 & 29.22 \\
\hline & Right ES & 9.95 & 14.58 & 88.41 \\
\hline & Left & & & \\
\hline \multirow[t]{5}{*}{ DJIM } & VaR & -22.62 & 7.38 & 28.22 \\
\hline & Left ES & 0.01 & 8.65 & 183.39 \\
\hline & Right & & & \\
\hline & $\mathrm{VaR}$ & -22.98 & 7.02 & 27.21 \\
\hline & Right ES & 0.01 & 9.61 & 257.14 \\
\hline
\end{tabular}

Table 12: Correlation Matrix

\begin{tabular}{lrrrr}
\hline & \multicolumn{1}{c}{ SP500 } & \multicolumn{1}{l}{ SPEU } & \multicolumn{1}{c}{ SPAS50 } & \multicolumn{1}{l}{ DJIM } \\
\hline SP500 & 1 & 0.5743 & 0.1888 & 0.8866 \\
SPEU & 0.5743 & 1 & 0.3829 & 0.7501 \\
SPAS50 & 0.1888 & 0.3829 & 1 & 0.4197 \\
DJIM & 0.8866 & 0.7501 & 0.4197 & 1 \\
\hline
\end{tabular}


Table 13: EGARCH Estimates and the Ljung - Box Test

\begin{tabular}{|c|c|c|c|c|c|c|c|c|c|}
\hline & & \multicolumn{2}{|c|}{ Mean-Eq } & \multicolumn{2}{|c|}{ Variance -Eq } & \multirow[b]{2}{*}{ Beta } & \multirow[b]{2}{*}{ Gamma } & \multicolumn{2}{|c|}{ Ljung-Box: lag 5} \\
\hline \multirow{3}{*}{ SP500 } & & $\mathrm{Mu}$ & Ari & $\omega$ & Alpha & & & Test-Stat & P-Value \\
\hline & Coeff & 0.041 & -0.043 & -0.004 & -0.133 & 0.987 & 0.010 & 1.606 & 0.995 \\
\hline & t-stat & 4.838 & -2.842 & -2.543 & -16.470 & 445.018 & 3.857 & & \\
\hline \multirow{2}{*}{ SPEU } & Coeff & 0.034 & 0.004 & 0.003 & 0.111 & 0.984 & 0.128 & 6.344 & 0.075 \\
\hline & t-stat & 2.816 & 0.376 & 1.282 & -12.898 & 1066.78 & 10.048 & & \\
\hline \multirow{2}{*}{ SPAS50 } & Coeff & 0.041 & 0.068 & 0.005 & -0.064 & 0.988 & 0.126 & 2.421 & 0.523 \\
\hline & t-stat & 2.457 & 4.220 & 2.965 & -7.972 & 721.72 & 6.557 & & \\
\hline \multirow{2}{*}{ DJIM } & Coeff & 0.038 & 0.137 & -0.005 & -0.101 & 0.987 & 0.114 & 3.308 & 0.354 \\
\hline & t-stat & 3.028 & 9.118 & -2.741 & -11.219 & 1074.934 & 9.269 & & \\
\hline
\end{tabular}

Table 14: Sub-period1 - POT Risk Measures $\alpha=1 \%$

\begin{tabular}{llrl}
\hline \hline & & \multicolumn{1}{l}{ VaR } & \multicolumn{1}{l}{ ES } \\
\hline \hline \multirow{2}{*}{ SP500 } & RT & 0.0376 & 0.0442 \\
& LT & 0.00328 & 0.0423 \\
SPEU & RT & 0.0419 & 0.0501 \\
& LT & 0.0428 & 0.0529 \\
SPAS50 & RT & 0.0437 & 0.0598 \\
& LT & 0.0409 & 0.0543 \\
DJIM & RT & 0.0306 & 0.0357 \\
& LT & 0.0302 & 0.0364 \\
\hline \hline
\end{tabular}

Table 15: Sub-period1 - BMM Risk Measures $\alpha=1 \%$

\begin{tabular}{lll}
\hline \hline & Right-tail & Left-tail \\
\hline \hline SP500 & 0.0385 & 0.0385 \\
SPEU & 0.0447 & 0.0457 \\
SPAS50 & 0.0517 & 0.0482 \\
DJIM & 0.0218 & 0.0219 \\
\hline \hline
\end{tabular}


Table 16: Sub-period1 - POT Shape and Scale Estimates $\alpha=1 \%$

\begin{tabular}{llrrr}
\hline \hline & & Lower Bound & Best Estimate & Upper Bound \\
\hline \hline \multirow{5}{*}{ SP500 } & RT $(\xi)$ & -1.226 & -0.415 & -0.053 \\
& RT $(\sigma)$ & 0.007 & 0.013 & 0.033 \\
& LT $(\xi)$ & 1.235 & 0.2775 & -0.049 \\
& LT $(\sigma)$ & 0.0035 & 0.006 & 0.019 \\
& RT $(\xi)$ & -0.02 & -0.09 & -0.221 \\
SPEU & RT $(\sigma)$ & 0.011 & 0.011 & 0.014 \\
& LT $(\xi)$ & -0.136 & -0.015 & -0.015 \\
& LT $(\sigma)$ & 0.018 & 0.012 & 0.021 \\
& RT $(\xi)$ & 0.217 & 0.217 & 0.773 \\
SPAS50 & RT( $(\sigma)$ & 0.01 & 0.0096 & 0.015 \\
& LT $(\xi)$ & 0.111 & 0.111 & 0.678 \\
& LT $(\sigma)$ & 0.01 & 0.011 & 0.017 \\
& RT $(\xi)$ & -0.097 & -0.439 & -0.495 \\
DJIM & RT $(\sigma)$ & 0.01 & 0.011 & 0.014 \\
& LT $(\xi)$ & -0.061 & -0.061 & -0.234 \\
& LT $(\sigma)$ & 0.001 & 0.007 & 0.011 \\
\hline \hline
\end{tabular}

Table 17: Sub-period1 - BMM Shape and Scale Estimates $\alpha=1 \%$

\begin{tabular}{|c|c|c|c|c|}
\hline & & Lower Bound & $\begin{array}{l}\text { Best } \\
\text { Estimate }\end{array}$ & $\begin{array}{l}\text { Upper } \\
\text { Bound } \\
\end{array}$ \\
\hline \multirow{4}{*}{ SP500 } & $\mathrm{RT}(\xi)$ & -0.086 & 0.114 & 0.373 \\
\hline & $\mathrm{RT}(\sigma)$ & 0.006 & 0.007 & 0.009 \\
\hline & $\mathrm{LT}(\xi)$ & -0.089 & 0.057 & 0.265 \\
\hline & $\operatorname{LT}(\sigma)$ & 0.006 & 0.008 & 0.01 \\
\hline \multirow{4}{*}{ SPEU } & $\mathrm{RT}(\xi)$ & -0.0097 & 0.096 & 0.351 \\
\hline & $\mathrm{RT}(\sigma)$ & 0.007 & 0.009 & 0.012 \\
\hline & $\mathrm{LT}(\xi)$ & -0.096 & 0.0676 & 0.29 \\
\hline & $\operatorname{LT}(\sigma)$ & 0.008 & 0.0095 & 0.012 \\
\hline \multirow{4}{*}{ SPAS50 } & $\mathrm{RT}(\xi)$ & -0.053 & 0.1138 & 0.29 \\
\hline & $\mathrm{RT}(\sigma)$ & 0.008 & 0.0103 & 0.013 \\
\hline & $\mathrm{LT}(\xi)$ & -0.002 & 0.1871 & 0.405 \\
\hline & $\operatorname{LT}(\sigma)$ & 0.007 & 0.0092 & 0.012 \\
\hline \multirow{4}{*}{ DJIM } & $\mathrm{RT}(\xi)$ & 0.0074 & 0.269 & 0.63 \\
\hline & $\mathrm{RT}(\sigma)$ & 0.005 & 0.0051 & 0.006 \\
\hline & $\mathrm{LT}(\xi)$ & 0.133 & 0.3083 & 0.635 \\
\hline & $\mathrm{LT}(\sigma)$ & 0.005 & 0.005 & 0.005 \\
\hline
\end{tabular}


Table 18: Sub-period2 - POT Risk Measures $\alpha=1 \%$

\begin{tabular}{llrr}
\hline \hline & & \multicolumn{1}{l}{ VaR } & \multicolumn{1}{l}{ ES } \\
\hline \hline \multirow{2}{*}{ SP500 } & RT & 0.037 & 0.057 \\
& LT & 0.0435 & 0.065 \\
\multirow{2}{*}{ SPEU } & RT & 0.0314 & 0.058 \\
& LT & 0.0402 & 0.0578 \\
\multirow{2}{*}{ SPAS50 } & RT & 0.04 & 0.062 \\
& LT & 0.0496 & 0.0621 \\
DJIM & RT & 0.025 & 0.049 \\
& LT & 0.0355 & 0.0538 \\
\hline \hline
\end{tabular}

Table 19: Sub-period2 - BMM Risk Measures $\alpha=1 \%$

\begin{tabular}{lrr}
\hline & \multicolumn{1}{c}{ Right-tail } & \multicolumn{1}{c}{ Left-tail } \\
\hline \hline SP500 & 0.0385 & 0.0385 \\
SPEU & 0.0359 & 0.0404 \\
SPAS50 & 0.0439 & 0.0469 \\
DJIM & 0.0263 & 0.0297 \\
\hline \hline
\end{tabular}

Table 20: Sub-period2 - POT Shape and Scale Estimates $\alpha=1 \%$

\begin{tabular}{|c|c|c|c|c|}
\hline & & Lower Bound & Best Estimate & Upper Bound \\
\hline \multirow{4}{*}{ SP500 } & $\mathrm{RT}(\xi)$ & 0.185 & 0.185 & 0.833 \\
\hline & $\mathrm{RT}(\sigma)$ & 0.014 & 0.014 & 0.023 \\
\hline & $\mathrm{LT}(\xi)$ & 0.174 & 0.174 & 0.69 \\
\hline & $\mathrm{LT}(\sigma)$ & 0.014 & 0.014 & 0.022 \\
\hline \multirow{4}{*}{ SPEU } & $\mathrm{RT}(\xi)$ & 0.121 & 0.512 & 1.447 \\
\hline & $\mathrm{RT}(\sigma)$ & 0.01 & 0.009 & 0.017 \\
\hline & $\operatorname{LT}(\xi)$ & 0.169 & 0.169 & 0.683 \\
\hline & $\mathrm{LT}(\sigma)$ & 0.01 & 0.012 & 0.018 \\
\hline \multirow{4}{*}{ SPAS50 } & $\mathrm{RT}(\xi)$ & 0.042 & 0.298 & 0.833 \\
\hline & $\mathrm{RT}(\sigma)$ & 0.01 & 0.01 & 0.016 \\
\hline & $\mathrm{LT}(\xi)$ & -0.248 & -0.129 & -0.129 \\
\hline & $\mathrm{LT}(\sigma)$ & 0.021 & 0.018 & 0.023 \\
\hline \multirow{4}{*}{ DJIM } & $\mathrm{RT}(\xi)$ & 0.091 & 0.526 & 1.668 \\
\hline & $\mathrm{RT}(\sigma)$ & 0.01 & 0.008 & 0.017 \\
\hline & $\mathrm{LT}(\xi)$ & 0.169 & 0.169 & 0.732 \\
\hline & $\operatorname{LT}(\sigma)$ & 0.01 & 0.012 & 0.02 \\
\hline
\end{tabular}


Table 21: Sub-period2 - BMM Shape and Scale Estimates $\alpha=1 \%$

\begin{tabular}{|c|c|c|c|c|}
\hline & & Lower Bound & Best Estimate & Upper Bound \\
\hline \multirow{4}{*}{ SP500 } & $\mathrm{RT}(\xi)$ & -0.086 & 0.1135 & 0.373 \\
\hline & $\mathrm{RT}(\sigma)$ & 0.006 & 0.0069 & 0.009 \\
\hline & $\mathrm{LT}(\xi)$ & 0.089 & 0.0643 & 0.265 \\
\hline & $\operatorname{LT}(\sigma)$ & 0.006 & 0.0077 & 0.01 \\
\hline \multirow{4}{*}{ SPEU } & $\mathrm{RT}(\xi)$ & 0.209 & 0.4409 & 0.734 \\
\hline & $\mathrm{RT}(\sigma)$ & 0.05 & 0.0056 & 0.007 \\
\hline & $\mathrm{LT}(\xi)$ & 0.105 & 0.3982 & 0.781 \\
\hline & $\mathrm{LT}(\sigma)$ & 0.006 & 0.0073 & 0.009 \\
\hline \multirow{4}{*}{ SPAS50 } & $\mathrm{RT}(\xi)$ & 0.019 & 0.2568 & 0.297 \\
\hline & $\mathrm{RT}(\sigma)$ & 0.008 & 0.0095 & 0.012 \\
\hline & $\mathrm{LT}(\xi)$ & 0.094 & 0.3645 & 0.644 \\
\hline & $\operatorname{LT}(\sigma)$ & 0.007 & 0.0086 & 0.011 \\
\hline \multirow{4}{*}{ DJIM } & $\mathrm{RT}(\xi)$ & 0.057 & 0.182 & 0.302 \\
\hline & $\mathrm{RT}(\sigma)$ & 0.005 & 0.0054 & 0.007 \\
\hline & $\mathrm{LT}(\xi)$ & 0.16 & 0.3637 & 0.541 \\
\hline & $\operatorname{LT}(\sigma)$ & 0.005 & 0.0055 & 0.007 \\
\hline
\end{tabular}

Table 22: Sub-period3 - POT Risk Measures $\alpha=1 \%$

\begin{tabular}{llcl}
\hline \hline & & VaR & ES \\
\hline \multirow{2}{*}{ SP500 } & RT & 0.0315 & 0.0418 \\
& LT & 0.0318 & 0.0416 \\
SPEU & RT & 0.0343 & 0.0464 \\
& LT & 0.0372 & 0.0442 \\
SPAS50 & RT & 0.0322 & 0.0418 \\
& LT & 0.0337 & 0.0407 \\
DJIM & RT & 0.0272 & 0.0334 \\
& LT & 0.0276 & 0.0363 \\
\hline \hline
\end{tabular}

Table 23: Sub-period3 - BMM Risk Measures $\alpha=1 \%$

\begin{tabular}{lll}
\hline \hline & Right-tail & Left-tail \\
\hline \hline SP500 & 0.0327 & 0.0411 \\
SPEU & 0.0398 & 0.0415 \\
SPAS50 & 0.0357 & 0.041 \\
DJIM & 0.03038 & 0.0368 \\
\hline \hline
\end{tabular}


Table 24: Sub-period3 - POT Shape and Scale Estimates $\alpha=1 \%$

\begin{tabular}{|c|c|c|c|c|}
\hline & & Lower Bound & Best Estimate & Upper Bound \\
\hline \multirow{4}{*}{ SP500 } & RT $(\xi)$ & 0.077 & 0.077 & 0.667 \\
\hline & $\mathrm{RT}(\sigma)$ & 0.009 & 0.009 & 0.014 \\
\hline & $\mathrm{LT}(\xi)$ & 0.114 & 0.114 & 0.67 \\
\hline & $\operatorname{LT}(\sigma)$ & 0.01 & 0.008 & 0.012 \\
\hline \multirow{4}{*}{ SPEU } & $\mathrm{RT}(\xi)$ & 0.206 & 0.206 & 0.68 \\
\hline & $\mathrm{RT}(\sigma)$ & 0.1 & 0.007 & 0.011 \\
\hline & $\mathrm{LT}(\xi)$ & -0.191 & -0.191 & 0.015 \\
\hline & $\operatorname{LT}(\sigma)$ & 0.1 & 0.011 & 0.015 \\
\hline \multirow{4}{*}{ SPAS50 } & RT $(\xi)$ & 0.153 & 0.153 & 0.687 \\
\hline & $\mathrm{RT}(\sigma)$ & 0.007 & 0.007 & 0.01 \\
\hline & $\mathrm{LT}(\xi)$ & -0.339 & -0.189 & -0.189 \\
\hline & $\operatorname{LT}(\sigma)$ & 0.11 & 0.01 & 0.015 \\
\hline \multirow{4}{*}{ DJIM } & $\mathrm{RT}(\xi)$ & -0.248 & -0.099 & -0.099 \\
\hline & $\mathrm{RT}(\sigma)$ & 0.001 & 0.008 & 0.011 \\
\hline & $\mathrm{LT}(\xi)$ & 0.106 & 0.106 & 0.515 \\
\hline & $\operatorname{LT}(\sigma)$ & 0.001 & 0.007 & 0.01 \\
\hline
\end{tabular}

Table 25: Sub-period3 - BMM Shape and Scale Estimates $\alpha=1 \%$

\begin{tabular}{llrrr}
\hline \hline & & Lower Bound & Best Estimate & Upper Bound \\
\hline \hline \multirow{5}{*}{ SP500 } & RT $(\xi)$ & 0.055 & 0.2823 & 0.52 \\
& $\mathrm{RT}(\sigma)$ & 0.005 & 0.0057 & 0.007 \\
& $\mathrm{LT}(\xi)$ & 0.272 & 0.6752 & 0.93 \\
& $\mathrm{LT}(\sigma)$ & 0.003 & 0.0037 & 0.005 \\
& $\mathrm{RT}(\xi)$ & -0.012 & 0.1539 & 0.353 \\
SPEU & $\mathrm{RT}(\sigma)$ & 0.006 & 0.0075 & 0.01 \\
& $\mathrm{LT}(\xi)$ & 0.125 & 0.4004 & 0.699 \\
& $\mathrm{LT}(\sigma)$ & 0.004 & 0.0046 & 0.006 \\
& $\mathrm{RT}(\xi)$ & -0.033 & 0.1877 & 0.403 \\
SPAS50 & $\mathrm{RT}(\sigma)$ & 0 & 0.0069 & 0.009 \\
& $\mathrm{LT}(\xi)$ & 0.159 & 0.4854 & 0.874 \\
& $\mathrm{LT}(\sigma)$ & 0.003 & 0.041 & 0.05 \\
& $\mathrm{RT}(\xi)$ & 0.1 & 0.5094 & 0.928 \\
DJIM & $\mathrm{RT}(\sigma)$ & 0.003 & 0.0032 & 0.005 \\
& $\mathrm{LT}(\xi)$ & 0.172 & 0.6165 & 0.993 \\
& $\mathrm{LT}(\sigma)$ & 0.003 & 0.0035 & 0.05 \\
\hline \hline
\end{tabular}




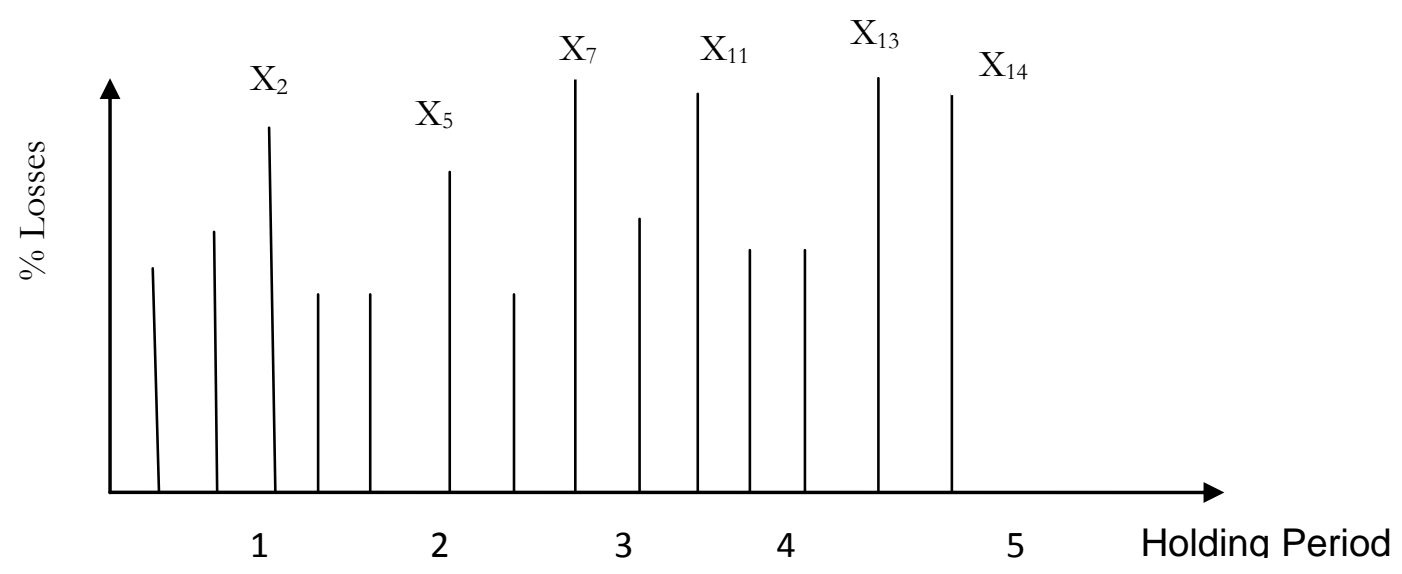

Figure 1. Hypothetical return series for a long position on the SP500 index during years $1,2,3,4$, and 5 .

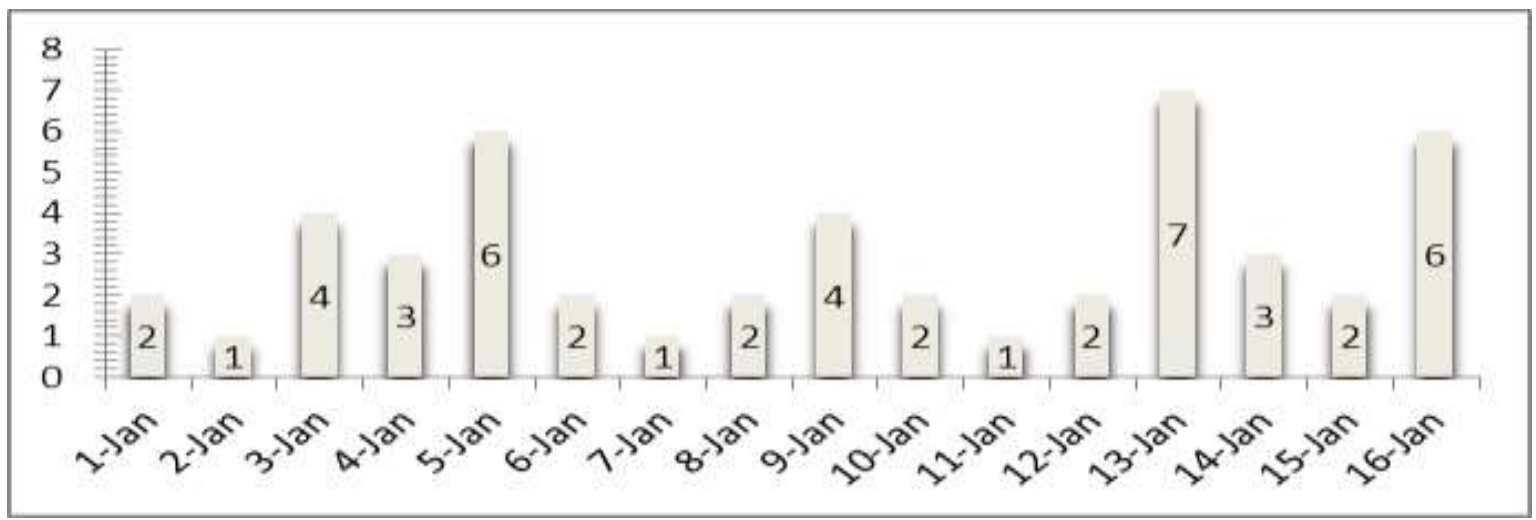

Figure 2: A hypothetical extreme return distribution with a threshold $\mathrm{u}=3$.

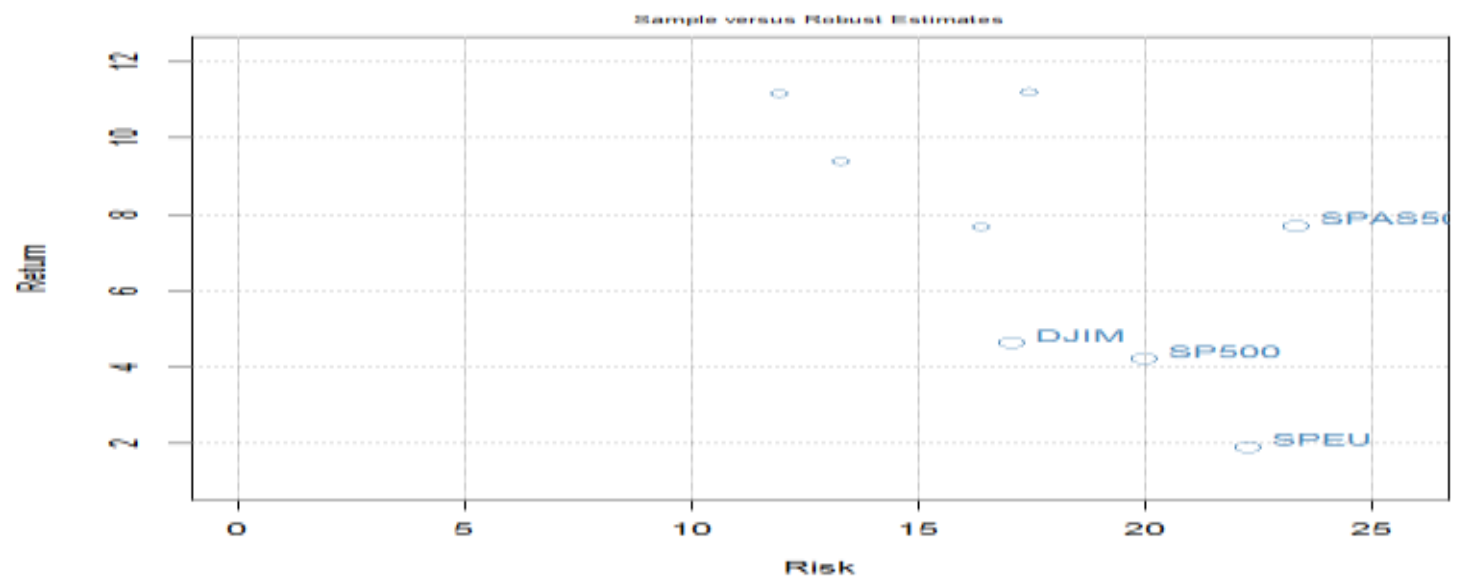

Figure 3: Risk-reward plot. 


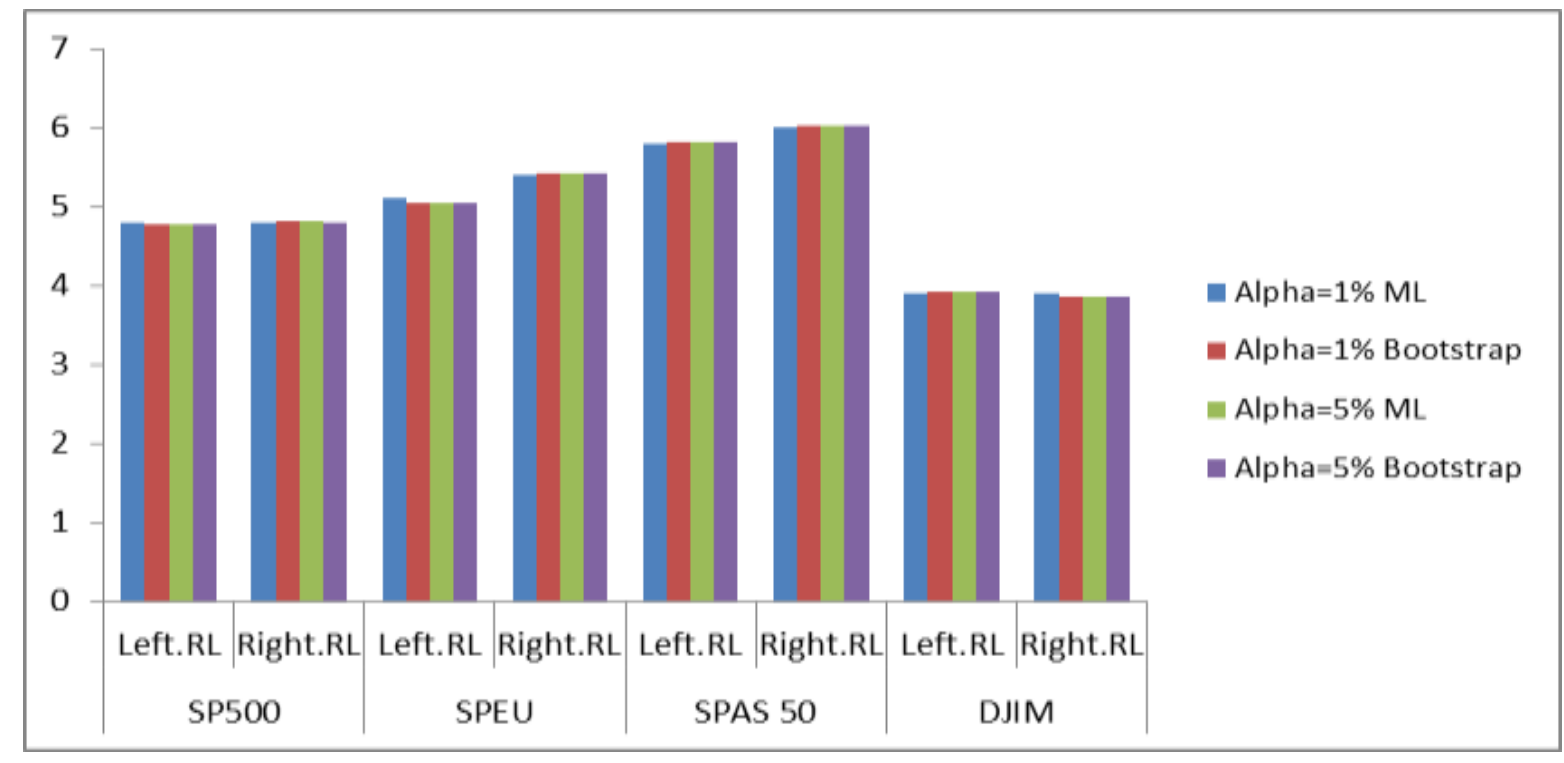

Figure 4: BMM comparative return levels.

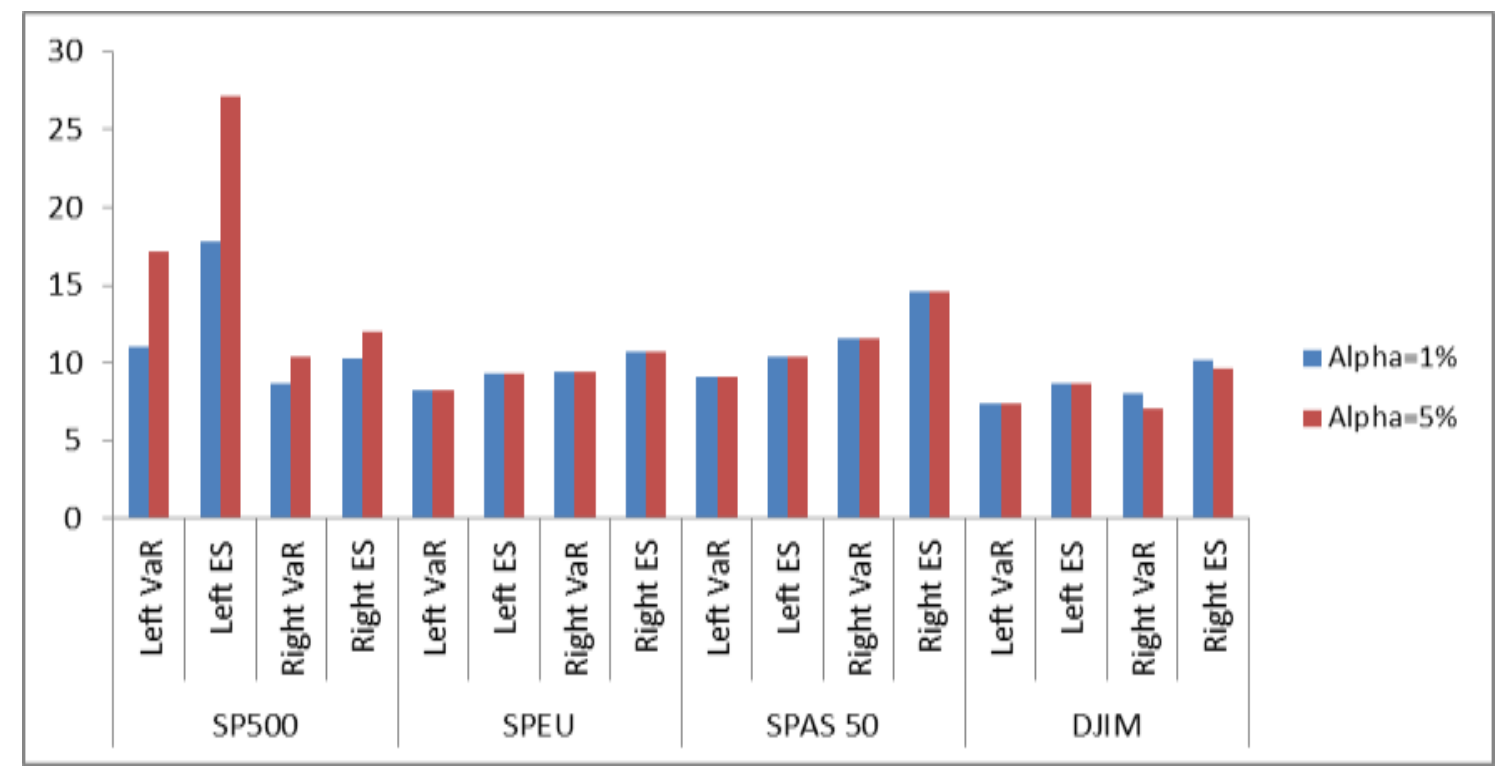

Figure 5: POT comparative risk measures. 


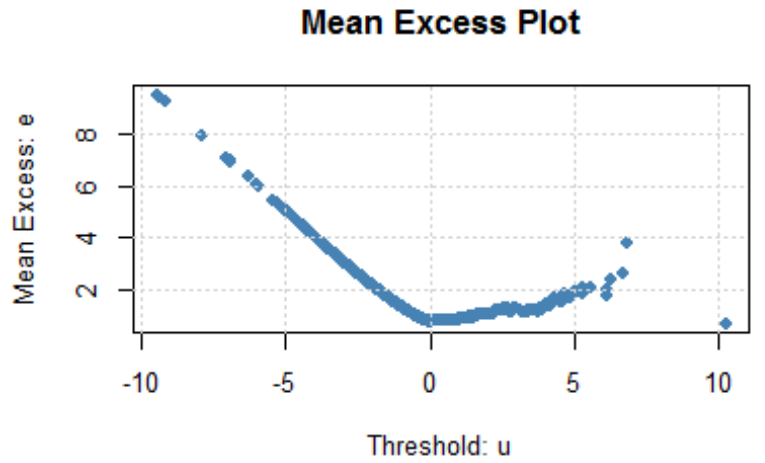

Tail of Underlying Distribution

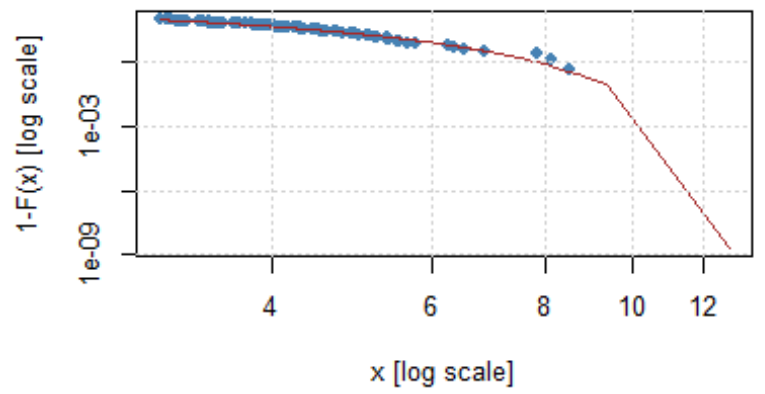

QQ-Plot of Residuals

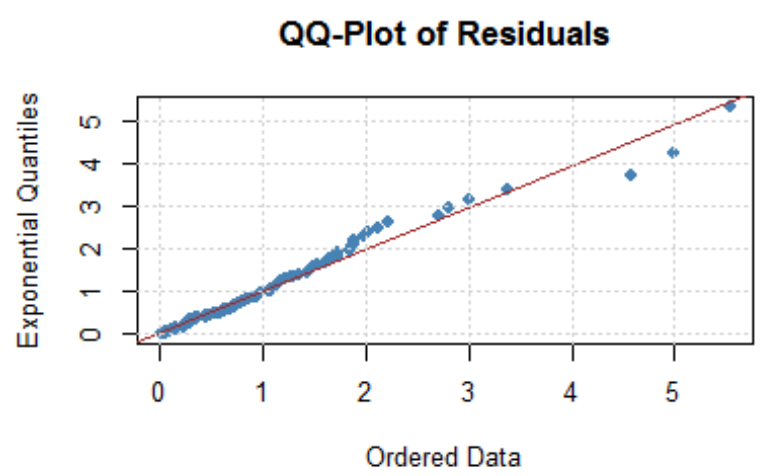

Figure 6: Checking the GPD for the SPAS50.
Excess Distribution

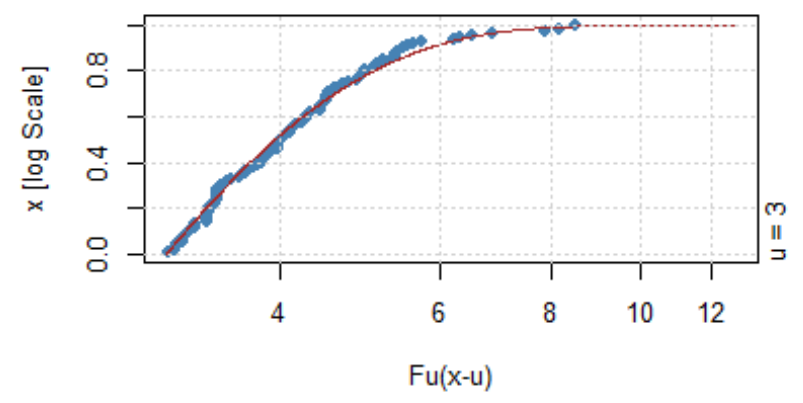

Scatterplot of Residuals

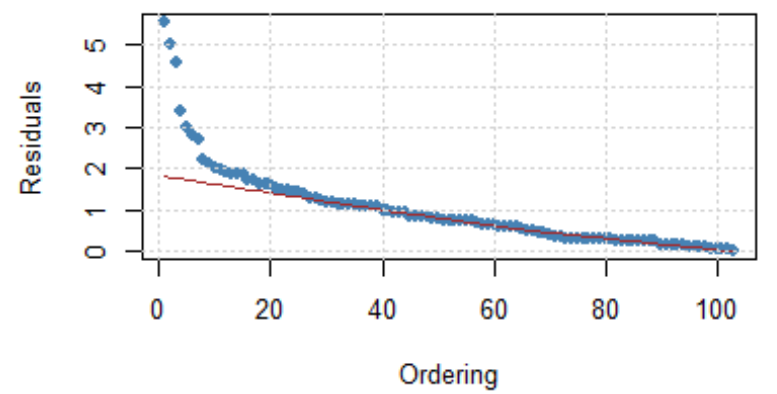




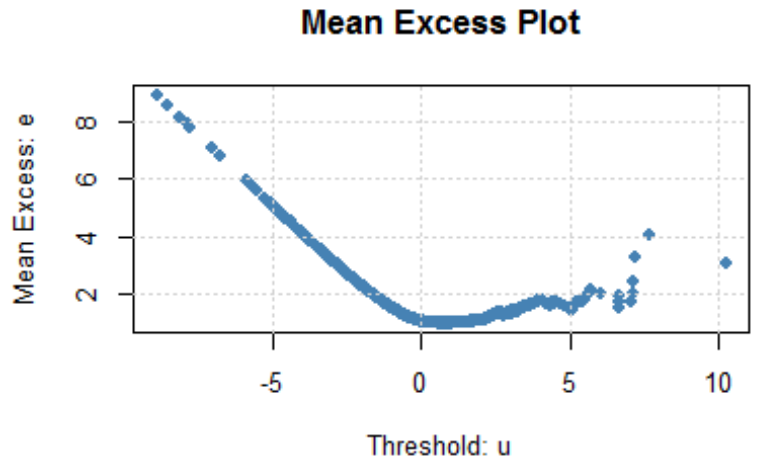

Tail of Underlying Distribution

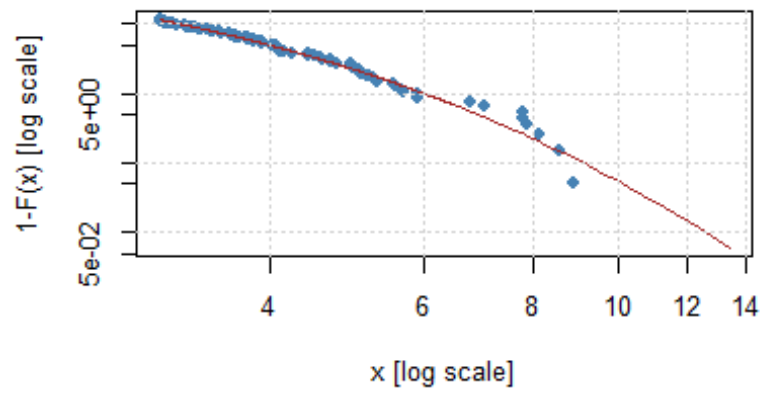

QQ-Plot of Residuals

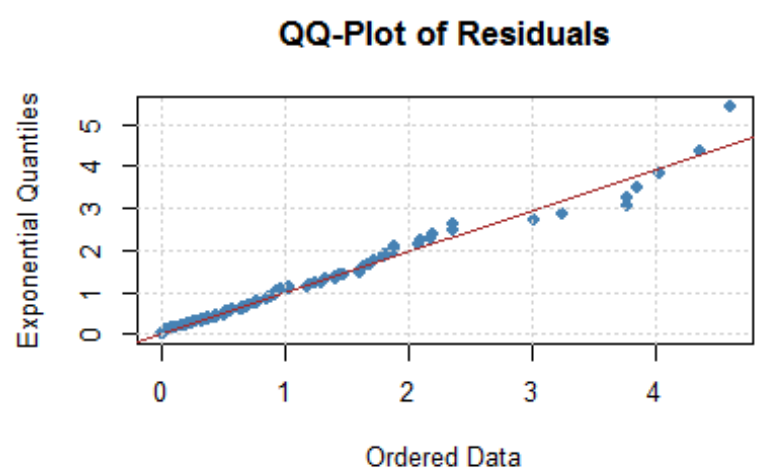

Figure 7: Checking the GPD for the DJIM.
Excess Distribution

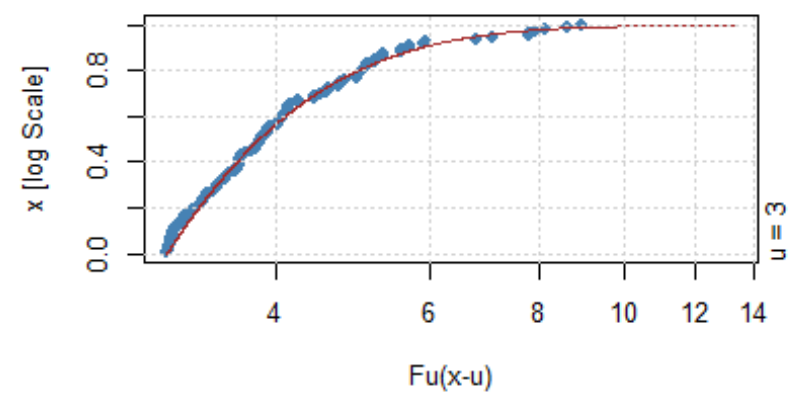

Scatterplot of Residuals

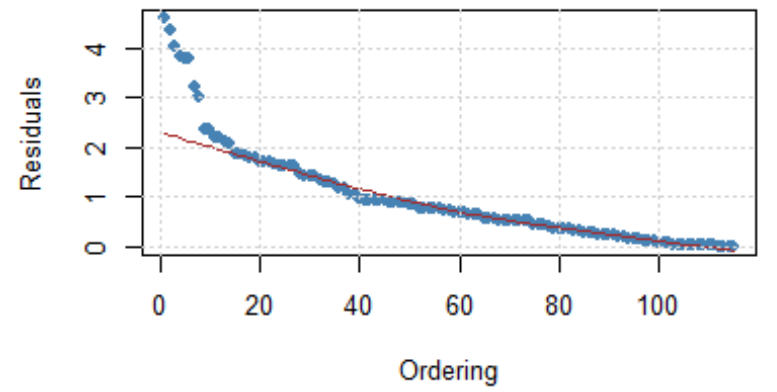


Mean Excess Plot

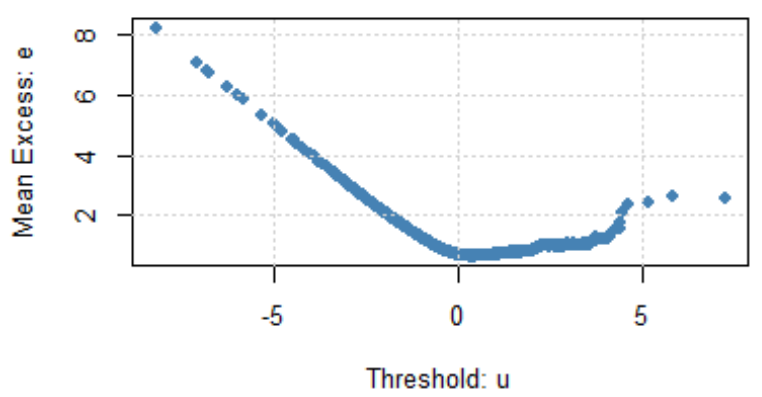

Tail of Underlying Distribution

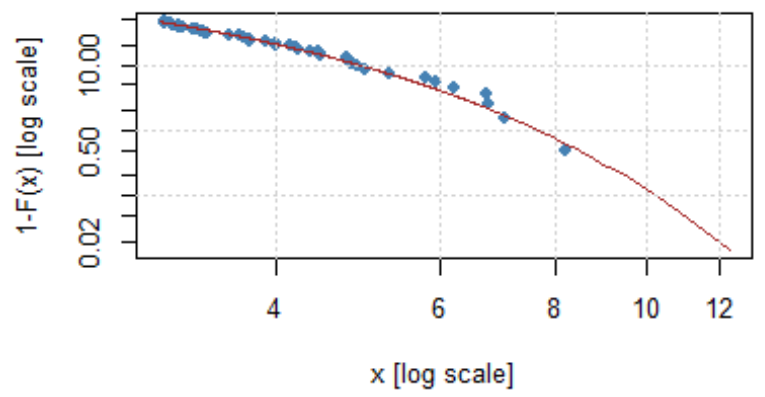

QQ-Plot of Residuals

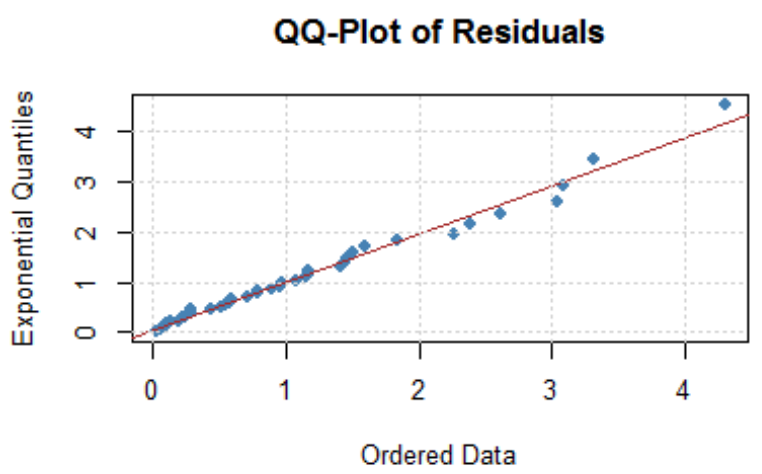

Figure 8: Checking the GPD for the SPEU.
Excess Distribution

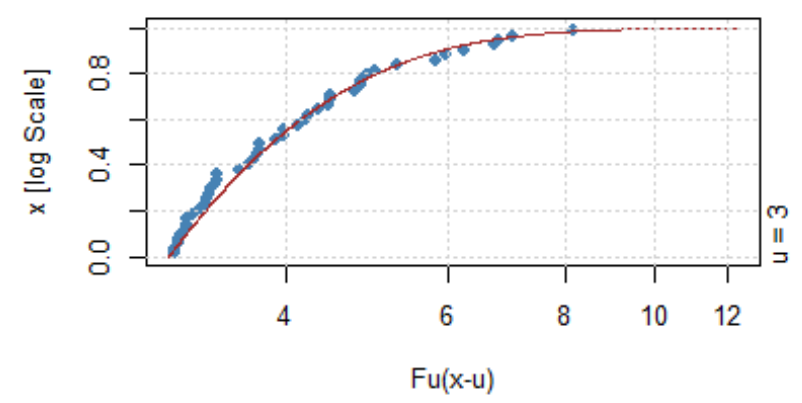

Scatterplot of Residuals

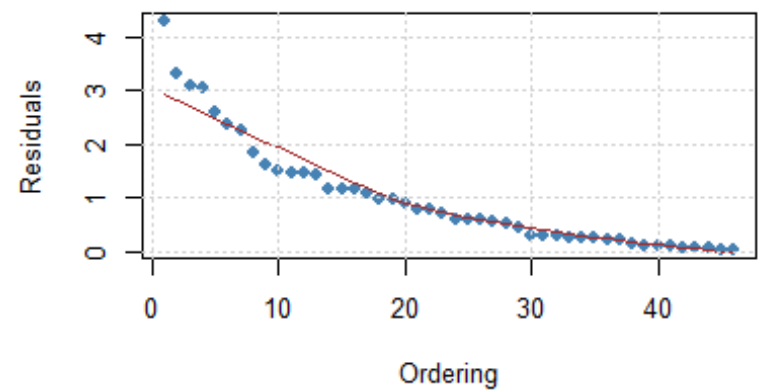




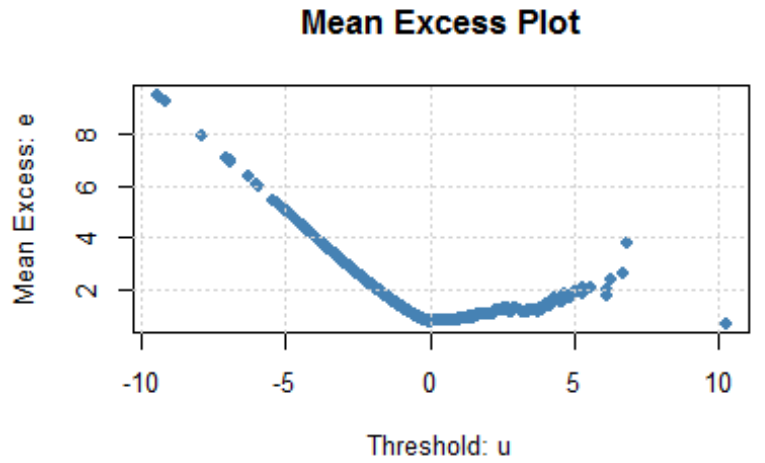

Tail of Underlying Distribution

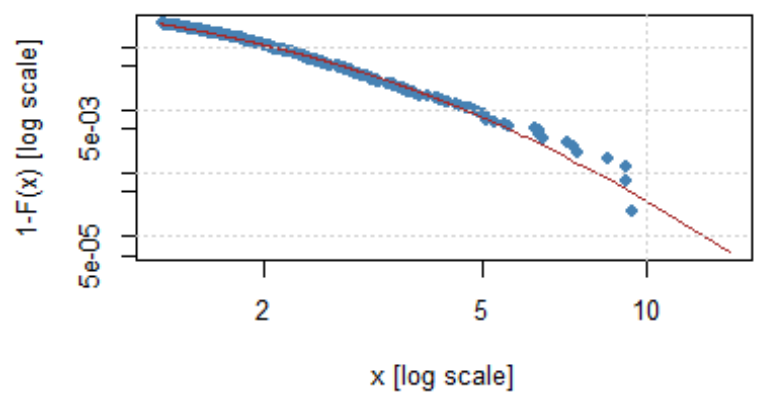

QQ-Plot of Residuals

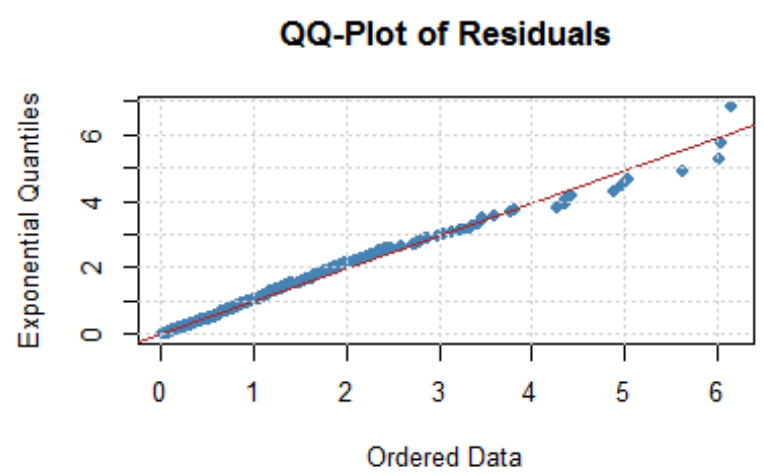

Figure 9: Checking the GPD for the SP500.
Excess Distribution

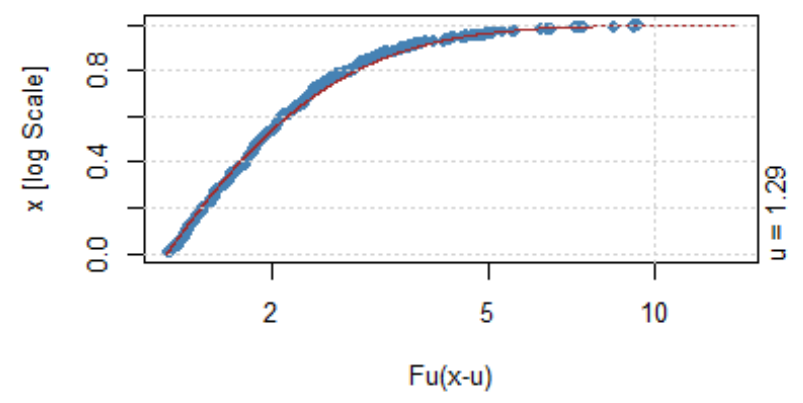

Scatterplot of Residuals

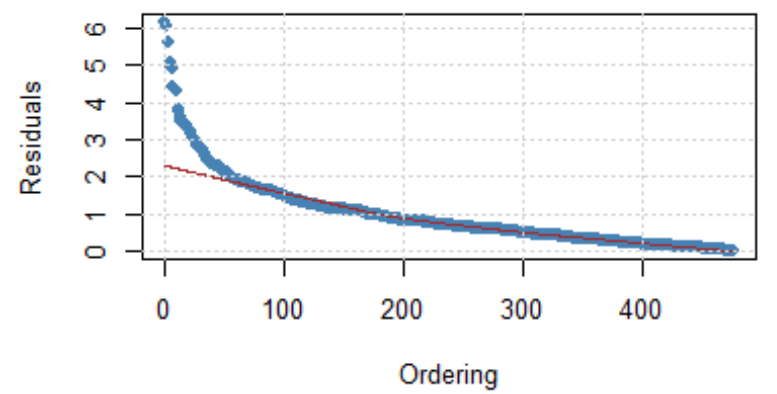

